\title{
A role for a-Synuclein in axon growth and its implications in corticostriatal glutamatergic plasticity in Parkinson's disease
}

Meir Schechter ${ }^{1}$, Jessica Grigoletto ${ }^{1}$, Suaad Abd-Elhadi ${ }^{1}$, Hava Glickstein², Alexander Friedman³ , Geidy E. Serrano ${ }^{4}$, Thomas G. Beach ${ }^{4}$ and Ronit Sharon ${ }^{1 *}$

\begin{abstract}
Background: a-Synuclein (a-Syn) is a protein implicated in the pathogenesis of Parkinson's disease (PD). a-Syn has been shown to associate with membranes and bind acidic phospholipids. However, the physiological importance of these associations to the integrity of axons is not fully clear.

Methods: Biochemical, immunohistochemical and ultrastructural analyses in cultured neurons, transgenic mouse brains, PD and control human brains.

Results: We analyzed the ultrastructure of cross-sectioned axons localized to white matter tracts (WMTs), within the dorsal striatum of old and symptomatic a-Syn transgenic mouse brains. The analysis indicated a higher density of axons of thinner diameter. Our findings in cultured cortical neurons indicate a role for a-Syn in elongation of the main axon and its collaterals, resulting in enhanced axonal arborization. We show that a-Syn effect to enhance axonal outgrowth is mediated through its activity to regulate membrane levels of the acidic phosphatidylinositol 4 , 5-bisphosphate $\left(\mathrm{PI}_{4}, 5 \mathrm{P}_{2}\right)$. Moreover, our findings link a-Syn- enhanced axonal growth with evidence for axonal injury. In relevance to disease mechanisms, we detect in human brains evidence for a higher degree of corticostriatal glutamatergic plasticity within WMTs at early stages of PD. However, at later PD stages, the respective WMTs in the caudate are degenerated with accumulation of Lewy pathology.

Conclusions: Our results show that through regulating PI4,5P 2 levels, $\mathrm{a}-\mathrm{Syn}$ acts to elongate the main axon and collaterals, resulting in a higher density of axons in the striatal WMTs. Based on these results we suggest a role for a-Syn in compensating mechanisms, involving corticostriatal glutamatergic plasticity, taking place early in PD.
\end{abstract}

Keywords: Parkinson's disease, Corticostriatal axons, a-Synuclein, Phosphatidylinositol 4,5-bisphosphate (PI4,5P 2 ), White matter tracts (WMTs), Axonal injury, Axonal growth

\footnotetext{
* Correspondence: ronitsh@ekmd.huji.ac.il

'Department of Biochemistry and Molecular Biology, IMRIC, The Hebrew University-Hadassah Medical School, Ein Kerem, 9112001 Jerusalem, Israel Full list of author information is available at the end of the article
}

C C The Author(s). 2020 Open Access This article is licensed under a Creative Commons Attribution 4.0 International License, which permits use, sharing, adaptation, distribution and reproduction in any medium or format, as long as you give appropriate credit to the original author(s) and the source, provide a link to the Creative Commons licence, and indicate if changes were made. The images or other third party material in this article are included in the article's Creative Commons licence, unless indicated otherwise in a credit line to the material. If material is not included in the article's Creative Commons licence and your intended use is not permitted by statutory regulation or exceeds the permitted use, you will need to obtain permission directly from the copyright holder. To view a copy of this licence, visit http://creativecommons.org/licenses/by/4.0/ The Creative Commons Public Domain Dedication waiver (http://creativecommons.org/publicdomain/zero/1.0/) applies to the data made available in this article, unless otherwise stated in a credit line to the data. 


\section{Background}

$\alpha$-Synuclein ( $\alpha$-Syn) is a protein known for its critical roles in the cytopathology and genetics of PD [1]. In the brain, $\alpha$-Syn pathology in the form of Lewy bodies and neurites, is strongly associated with severity of the disease and propagates in an ordered and predictable regional pattern $[2,3]$. Neuroanatomy studies suggest that the length and caliber of axons, together with the degree of myelination, determine neuronal vulnerability to Lewy pathology [4-6]. Specifically, susceptible neuronal cells may be projection neurons that express $\alpha$-Syn and generate long and thin axon, which is poorly or unmyelinated.

Phylogenetic studies indicated a remarkable degree of $\alpha$ Syn sequence conservation throughout the evolution of vertebrate branches $[7,8]$ and identified two homologous proteins, $\beta$-Syn and $\gamma$-Syn. Analysis of the amino acid sequence of $\alpha$-Syn protein indicated the occurrence of a 11mer repeats which make up a conserved apolipoproteinlike class- $\mathrm{A}_{2}$ helix [9]. These structural homologies provided the rationale for investigating the role of $\alpha$-Syn associations with membrane lipids in its pathophysiology. Importantly, the phylogenetic studies also indicated the absence of $\alpha$-Syn expression in invertebrates, including arthropods and cephalopods that possess a simple central nervous system [10]. Suggesting a possible involvement of $\alpha$-Syn in the development of vertebrate's brain complexity.

The cortex connects topologically with striatum through corticostriatal connections that play a central role in developing complex intentional-directed behaviors. Different regions of striatum have been associated with different cortical functions, including, emotions, cognition and motor control. Cortical glutamatergic efferent enter the striatum through striatal white matter tracts (WMTs), then make striatal synaptic contacts that influence the output nuclei of the basal ganglia [11]. In $\mathrm{PD}$, degeneration of dopamine-containing neurons in the substantia nigra pars compacta $(\mathrm{SNc})$, diminishes dopamine-containing innervations of the striatum and results in abnormal functioning of the striatum. Importantly, plasticity of the corticostriatal glutamatergic pathway is suggested to accommodate the loss of dopamine in early stages of the disease [12].

Collateral axon branching is a multifaceted mechanism controlled by numerous factors. One such factor is phosphatidylinositol 4,5-bisphosphate ( $\left.\mathrm{PI} 4,5 \mathrm{P}_{2}\right)$, a phosphorylated derivative of the membrane phospholipid, phosphatidylinositol (PI) [13]. PI4,5P $\mathrm{P}_{2}$ is generally formed through phosphorylation by members of the type-1 phosphatidylinositol phosphate-5 kinase family (PIPKI). The three members of PIPKI family, PIPKI $\alpha, \beta$ and $\gamma$, were shown to play differential roles in neurite formation and elongation. Key proteins involved in mechanisms of axonal elongation and branching were shown to recruit members of PIPKI to this process.
Interestingly, PIPKI $\alpha$ and PIPKI $\beta$ were shown to suppress the elongation of axons [14-17]. However, PIPKI $\gamma$ was implicated in axon elongation and organization of the growth cone $[18,19]$.

We discover a role for $\alpha$-Syn-associations with $\mathrm{PI}_{4}, 5 \mathrm{P}_{2}$ in elongation of axons and collaterals. In accord, we identify a remarkable increase in the density of lowdiameter axons within WMTs localized to the dorsal striatum of old and symptomatic $\alpha$-Syn tg mouse brains. Using axonal and synaptic markers, we demonstrate a higher density of glutamatergic axons within corticostriatal WMTs and glutamatergic terminals, in the caudate of postmortem human brains affected with PD at early stages of the disease. We suggest that $\alpha$-Syn effect to increase axon outgrowth underlies the reported glutamatergic plasticity, taking place early in PD.

\section{Methods}

\section{Human brains}

Formalin fixed, paraffin embedded brain sections, containing the caudate and internal capsule, of advanced PD (Braak stage 5-6) and age-matched control brains, were supplied by the Multiple Sclerosis Society Tissue Bank, funded by the Multiple Sclerosis Society of Great Britain and Northern Ireland, registered charity 207,495. Additional brain sections of early PD cases (Unified stage IIa-IIb [3]) and relevant control brains were provided by the Banner Sun Health Research Institute, Sun City, Arizona, USA (Supplementary Table S1). The approval for the use of human tissue material was obtained from the Peer Review Panel of the Parkinson's UK Brain Bank and the Brain and Body Donation Program at Sun Health Research Institute; the latter's operations are approved by the Western Institutional Review Board (Seattle, WA, USA).

\section{Mice}

The human PrP-A53T $\alpha$-Syn tg mouse line [20] was purchased from Jackson Laboratory (Bar Harbor, ME, USA) as hemizygous; cross-bred with $\alpha-\mathrm{Syn}^{-1-}$ C57BL/ 6JOlaHsd mice (Harlan Laboratories, Jerusalem, Israel [21]) to silence endogenous mouse $\alpha$-Syn; and then bred to achieve homozygosity of the human A53T $\alpha$-Syn transgene. $\alpha-\mathrm{Syn}^{-/-}$C57BL/6JOlaHsd genotype was used as control mice [21]. The PrP-A53T $\alpha$-Syn tg model was shown in previous studies to develop motor disabilities and to accumulate $\alpha$-Syn pathology in an age-dependent manner. That is, mice appear generally healthy and show no evidence of $\alpha$-Syn pathology up to the age of 8-9 months [20, 22, 23]. However, at 12 months of age and older, the large majority of mice in the colony show signs of motor disabilities accompanied with pathogenic accumulations of $\alpha$-Syn in the central nervous system. The number of sick mice grow with age and the oldest 
mice in the colony are $\sim 16$ months old. All animal welfare and experimental protocols were approved by the Committee for the Ethics of Animal Experiments of the Hebrew University of Jerusalem NIH approval \# OPRRA01-5011 (Permit number: MD-16-14,826-3).

Thy-1 hWT $\alpha$-Syn mice [24, 25] were obtained from Prof. Eliezer Masliah (UCSD, USA). Control mice were non-transgenic littermates. The Thy- 1 hWT $\alpha$-Syn mice show early signs of learning and motor disabilities at 24 months of age, which worsen at 8-10 months of age $[25,26] . \alpha$-Syn pathology for the Thy-1 hWT $\alpha$-Syn mice was demonstrated at $8-12$ months of age $[23,25]$.

5XFAD and control mice [27] were bred and aged at Prof. Dan Frenkel's laboratory (Tel -Aviv University). This mouse model shows accumulation of amyloid pathology, starting at the age of 4 months, in addition to cognitive impairment, starting at 6 months of age.

Mice were housed at a 12-h dark/light cycle and were allowed free access to food and water. This study was carried out in strict accordance with the recommendations in the Guide for the Care and Use of Laboratory Animals of the National Institutes of Health. Adequate measures were taken to minimize pain and suffering.

\section{Transmission electron microscopy}

Mice were anesthetized and perfused in Karnovsky's fixative solution ( $2 \%$ formaldehyde and $2.5 \%$ glutaraldehyde in 0.1 M Sodium Cacodylate buffer, pH 7.4). Mouse brains were removed and $100 \mu \mathrm{m}$ coronal sections were obtained using a vibratome (Leica Biosystems, IL, USA). Brain sections were fixed in Karnovsky's fixative solution for $2 \mathrm{~h}$ at room temperature and then transferred to $4{ }^{\circ} \mathrm{C}$ for an additional $24 \mathrm{~h}$. Sections were washed four times with $0.1 \mathrm{M}$ sodium cacodylate buffer $(\mathrm{pH} 7.3)$ and incubated for $1 \mathrm{~h}$ in $1 \%$ osmium tetroxide, $1.5 \%$ potassium ferricyanide in sodium cacodylate. Sections were then washed 4 times in the same buffer; dehydrated with graded series of ethanol solutions $(30,50,70,80,90$, 95\%) for 10 min each; then in $100 \%$ ethanol 3 times for $20 \mathrm{~min}$ each; followed by two changes of propylene oxide. Brain sections were infiltrated with series of epoxy resin, $(25,50,75,100 \%)$ for $24 \mathrm{~h}$ each and polymerized in the oven at $60^{\circ} \mathrm{C}$ for $48 \mathrm{~h}$. The blocks were sectioned by an ultramicrotome (Ultracut E, Riechert-Jung, Ontario, Canada) and sections of $80 \mathrm{~nm}$ were stained with uranyl acetate and lead citrate. Sections were observed using a Jeol JEM 1400 Plus Transmission Electron Microscope and pictures were taken using a Gatan Orius CCD camera.

\section{Cell cultures}

HEK $293 \mathrm{~T}, \mathrm{HeLa}$ and SH-SY5Y cell lines were maintained in Dulbecco's modified Eagle's medium (DMEM) supplemented with $10 \%$ FBS; $2 \%$ L-glutamine; $1 \%$ penicillin/streptomycin, sodium-pyruvate and nonessential amino acids (Biological Industries, BeitHaemek, Israel). SK-mel2 cells express detectable levels of endogenous $\alpha$-Syn, however, these are lowered with passages. Thus, experiments were performed between weeks 2-4 from thawing a frozen aliquot. Cells were maintained in minimal essential medium (MEM; SigmaAldrich, Rehovot, Israel) supplemented with 10\% FBS; $1 \%$ L-glutamine, penicillin/streptomycin and sodiumpyruvate. Cultures were maintained at $37^{\circ} \mathrm{C}$ in a $95 \%$ air/ $5 \% \mathrm{CO}_{2}$ humidified incubator.

\section{Plasmids}

Costume-ready Mission shRNA were from Sigma-Aldrich. Including, shSNCA (TRCN0000272292), shCntrl and shNIR2 (TRCN0000029763), that was successfully used previously [28]; pGFP-C1-PLC81-PH (Addgene \# 21179 [29] from Tobias Meyer); pEGFPC1-Sj-1-170 and GFPPIPKIY (Addgene \# 22294 [30] and \#22299 [31] from Pietro De Camilli); pFSy(1.1) GW (Addgene \# 27232 [32] from Pavel Osten). CFP-FKBP- PIPK and Lyn-FRB.

[33]. mCherry-NIR2, a kind gift from Jen Liou (UT Southwestern Medical Center). pFSy- $\alpha$-Syn was constructed by ligation of a full-length $\alpha$-Syn cDNA, amplified by PCR, with pFSy(1.1) GW, following digestion with AgeI-HF / Xba-I restriction enzymes. The following primers were used for $\alpha$-Syn amplification: forward: $5^{\prime}$ GAATCACCGGTGCCGCCACCATGGATGTATTCAT GAAAG G-3' and reverse: 5'-TAACTCTAGATTAG GCTTCAGGTTCGTAGT-3'.

\section{Viral production and transduction}

Lentiviral particles were produced by co-transfecting HEK $293 \mathrm{~T}$ cells with a set of three plasmids: $\mathrm{pCMV} \Delta \mathrm{R} 8.91$; pMD2.G; and a transfer plasmid, either pFSy(1.1) or pLKO-1-puro. Transfection was performed in $10 \mathrm{~cm}$ dishes $\left(2 \times 10^{6}\right.$ cells) using $50 \mu \mathrm{g}$ polyethylenimine (PEI) incubated with $12.5 \mu \mathrm{g}$ DNA at 1:1:1 $\mathrm{M}$ ratio for the three plasmids. 3-4 days after transfection, the conditioning medium was collected and spun for $5 \mathrm{~min}$ at $1500 \mathrm{xg}$ to remove cell debris, filtered through a $0.45 \mu \mathrm{m}$ membrane and spun at $93,000 \mathrm{xg}$ for $2 \mathrm{~h}$, at $4{ }^{\circ} \mathrm{C}$ in a swinging-bucket rotor. Pellets containing virus particles were collected in serum-free medium and stored at $-80^{\circ} \mathrm{C}$, in aliquots. Each aliquot was thawed once, immediately before use. Virus titer was determined for each preparation following transduction of naïve SH-SY5Y cells, by quantitative PCR using specific primers either for WPRE gene (pFSy plasmids): forward 5'-CCGTTGTCAGGCAACGTG-3' and reverse 5'-AGCTGACAGGTGGTGGCAAT-3'; or Puromycin resistance gene (pLKO-1-puro plasmids): forward, 5' -TCACCGAGCTGCAAGAACTCT-3' and reverse primer, 5'-CCCACACCTTGCCGATGT-3'. Primer sequence for human SNCA: forward: 5'-GCAGGGAGCA 
TTGCAGCAGC-3 and reverse 5 '-GGCTTCAGGTTCGT AGTCTTG-3'; G6PD: forward: 5'- CACCATCTGG TGGCTGTTC -3 and reverse 5'- TCACTCTGTT TGCGGATGTC - 3;

Viral transduction of cultured cells was performed by incubating the cells $\left(1.5 \times 10^{6}\right)$ in FBS-free DMEM, containing viral particles and polybreane $(4 \mu \mathrm{g} / \mathrm{ml})$ for $6 \mathrm{~h}$. The conditioning medium was then replaced with $10 \%$ FBS-supplemented DMEM. Viral transduction of primary cortical neurons was performed at 1 day in vitro (DIV) in full Neurobasal-A medium without polybreane.

\section{Primary cultures}

Cortical cultures were prepared from cortices, dissected from a day old (P1) C57BL/6 J or C57BL/6JOlaHsd mouse brains, as described previously [34]. Cells $(\sim 50$, $000)$ were plated onto coverslips, pre-coated with $12.5 \mathrm{\mu g} / \mathrm{ml}$ poly-D-lysine (Sigma-Aldrich) in a 12-well dish. Cortical neurons were maintained in Neurobasal-A medium (Gibco, Thermo Fisher Scientific, Petah Tikva, Israel) and supplemented with 2\% B-27 (Gibco, Thermo Fisher Scientific); $1 \%$ L-glutamine; $0.5 \%$ penicillin/ streptomycin. To eliminate glia cells, $1 \mu \mathrm{M}$ cytosine $\beta$-Darabinofuranoside (Ara-C; Sigma-Aldrich) was added to the culture at 1-2 DIV. Culture medium was partially (25-50\%) replaced every 4 days. Cultures were maintained at $37{ }^{\circ} \mathrm{C}$ in a $5 \% \mathrm{CO}_{2}$ humidified incubator.

Hippocampal cultures were prepared from CA1-CA3 regions dissected from a day old (P1) WT C57BL/6 J or $\alpha-\mathrm{Syn}^{-1-} \mathrm{C} 57 \mathrm{BL} / 6 \mathrm{JOlaHsd}$ mouse brains as described previously [34].

Mesencephalic neurons were prepared from brains of mice at E13.5 embryos as described [35].

Electroporation of primary neurons was performed on day of preparation. Neurons were electroporated using the Amaxa Nucleofector (Lonza, Tuas, Singapore) according to manufacturer's protocol [36]. $1.0 \times 10^{6}$ cells were suspended in $100 \mu \mathrm{l}$ of Ingenio electroporation solution (Mirus Bio LLC, Madison, WI, USA) containing $2.5 \mu \mathrm{g}$ of DNA, in a nucleofection cuvette using program $\mathrm{O}-05$. Cells were centrifuged to remove the electroporation medium and suspended in conditioning medium.

\section{Tissue punches}

Mouse brains were removed, washed with cold PBS and placed on ice. A coronal segment of the brain, containing Bregma $0-(-3)$ was removed. Tissue punches (pooled from both hemispheres) were taken using a needle $(1 \mathrm{~mm})$ from the dorsal striatum. Punches were weighed and stored at $-80^{\circ} \mathrm{C}$ until use. Tissue was homogenized by ten up-and-down strokes of Teflon Dounce homogenizer, in 10 volumes (weight/volume) of homogenization buffer containing HEPES, $20 \mathrm{mM}$; EDTA, $1 \mathrm{mM} ; \mathrm{MgCl}_{2}, 1 \mathrm{mM}$; sucrose, $0.32 \mathrm{M}$; a protease inhibitor cocktail (Sigma, Rehovot, Israel); and 1\% NP40 , at $4{ }^{\circ} \mathrm{C}$. The homogenates were centrifuged at 1500 $\mathrm{xg}$ for $10 \mathrm{~min}$ to remove cell debris. Protein samples $(30 \mu \mathrm{g})$ were loaded on a 10\% SDS-PAGE, and following electrophoresis, were transferred to a nitrocellulose membrane (Biorad, Petach Tikva, Israel). The membrane was blocked with $10 \%$ non-fat dry milk in $10 \mathrm{mM}$ Tris$\mathrm{HCl}, 150 \mathrm{mM} \mathrm{NaCl}, \mathrm{pH} 8.0$, containing $0.1 \%$ Tween-20 (TBST) for $1 \mathrm{~h}$. The membrane was then incubated at $4{ }^{\circ} \mathrm{C}$ for $16-18 \mathrm{~h}$ with the indicated antibody, in TBST. For antibody details see supplementary Table S2. Immunoreactive bands were detected with HRP-conjugated secondary antibody $(1: 10,000)$. The signal was visualized with EZ-ECL (Biological Industries, Beit Haemek, Israel), scanned by a Umax Magic Scan (Eastman Kodak, Rochester, NY, USA) and analyzed for density of each signal using UN-SCAN-IT GEL 3.1 software (Silk Scientific, Orem, UT, USA).

\section{FACS}

Analysis was performed as previously described [37] with some modifications. Cells were suspended and washed in clear DMEM; followed by 20 min fixation in $2 \%(\mathrm{v} / \mathrm{w})$ paraformaldehyde at $4{ }^{\circ} \mathrm{C}$; and permeabilization in $0.2 \%$ saponin in $1 \% \mathrm{BSA}(\mathrm{w} / \mathrm{v})$ for $15 \mathrm{~min}$ at $4{ }^{\circ} \mathrm{C}$. Cells were then incubated with anti $\alpha$-Syn antibody (MJFR1, 1:2000) and anti PI4,5 $\mathrm{P}_{2}$ antibody (1:200, see supplementary Table S2) for 90 min at $4{ }^{\circ} \mathrm{C}$ with gentle rolling; washed and probed with the respective secondary antibody for $30 \mathrm{~min}$ at room temperature. FACS analysis in SK-mel2 cells was performed 7-14 days following viral transduction. During this time effective $\alpha$ Syn knockdown was confirmed using rt-PCR and Western blotting. HEK 293 T cells were analyzed by FACS 48 $\mathrm{h}$ from transfection. Analyses were performed using BD LSRFortessa Cell Analyzer, equipped with 5 lasers (355, 405, 488, 561 and $640 \mathrm{~nm}$ ) and FLOWJO, LLC software. Mock-GFP, Sj-1 or PIPKI $\gamma$ expression were directly detected at $488 \mathrm{~nm}$ based on a GFP-tag. Each experiment also included adequate compensation controls. In each experiment a control, consisting of cells grown and processed in parallel, treated with ionomycin [38] $(10 \mu \mathrm{M})$ for $7 \mathrm{~min}$ at room temperature, was included. Gating was based on FSC, SSC and positive immunoreactivity for the relevant proteins (i.e., $\alpha$-Syn, $\mathrm{Sj}-1$ and PIPK $\gamma$ ). A total of 3000-4000 gated cells were counted in each experiment unless indicated differently.

\section{$\mathrm{PI} 4,5 \mathrm{P}_{2}$ detection by PH-PLC 81 -GFP biosensor}

HeLa cells were grown on cover slides coated with polyD-Lysine, in 12-well plates. Cells were co-transfected with PH-PLC $81-G F P$ and either WT, A53T or K10,12E $\alpha$-Syn expressing plasmids, using JetPRIME transfection reagent polyplus (Tamar, Rehovot, Israel). Forty eight 
hours post transfection, cells were incubated with $50 \mu \mathrm{g} /$ $\mathrm{ml}$ Alexa-647 Concanavalin (Con) A (molecular probes, Invitrogen, Rehovot, Israel) in DMEM, at $37^{\circ} \mathrm{C}$ for 10 min; washed in cold serum-free DMEM; and fixed with $4 \%$ paraformaldehyde for $10 \mathrm{~min}$, on ice. Cells were then washed one more time and permeabilized with $0.2 \%$ Triton X-100 in blocking solution (1.5\% BSA in PBS) for 5 $\mathrm{min}$ at room temperature. Cells were incubated with anti $\alpha$-Syn antibody, C20 (Santa Cruz, Dallas TX, US) at 1: 500 dilution, overnight at $4{ }^{\circ} \mathrm{C}$, followed by a secondary ab. Membrane to cytosolic signal ratio of PH-PLC $81-$ GFP was calculated using the NIS-Element AR Analysis 4.20.02 64-bit software (Nikon, Agentek, Tel Aviv, Israel). Membranes were defined by the ring-shaped ConA signal around the cell and differentiated from the cytoplasm of the cells.

\section{Immunocytochemistry (ICC)}

Primary neurons grown on cover slips, at 4 or 14 DIV were gently washed with warm HBSS (Biological Industries, Beit-Haemek, Israel), fixed with 2\% PFA for $20 \mathrm{~min}$ at room temperature and permeabilized with $0.5 \%$ saponin in $1 \%(\mathrm{w} / \mathrm{v})$ BSA for $30 \mathrm{~min}$, at room temperature. Cover slips were then incubated for $2 \mathrm{~h}$ at room temperature with the indicated primary antibodies (Supplementary Table S2) in 1\% (w/v) BSA, followed by 3 washes in PBS, 5 min each. Slides were then incubated with appropriate secondary ab, washed and mounted in vectashield $^{\bullet}$ mounting medium (Vector-labs, Burlingame, CA USA).

\section{Immunohistochemistry for mouse brain sections}

Paraffin-embedded, coronal mouse brain sections $(6 \mu \mathrm{M})$ were processed for immunostaining as previously described [39]. The antibodies used are listed in supplementary Table S2. Images were acquired using a Zeiss LSM 710 Axio Observer confocal Z1 laser scanning microscope, equipped with an argon laser 488, Diode 405-430 laser and HeNe 633 laser. Images at Fig. 3g; Fig. 5a and supplemtary 2B were captured at higher resulation using Nikon's A1R+ confocal microscope, equipped with an ultrahigh-speed resonant scanner and high-resolution digital galvano scanner, with four laser unit LU-N4S. Per each experiment, the exciting laser, intensity, background levels, photo multiplier tube (PMT) gain, contrast and electronic zoom were maintained constant. Antibody specific background was subtracted. The focus of each picture was obtained by choosing the plane with greatest fluorescent signal.

\section{Immunohistochemistry for human brains}

Slides containing formalin fixed, paraffin embedded brain sections of advanced PD and controls, immunoreacted with anti SMI-32 ab [40] or anti $\alpha$-Syn antibody
(BD Transduction Labs), were provided by the Multiple Sclerosis Society Tissue Bank. Otherwise, slides were processed for immunostaining as previously described [39]. The antibodies used are listed in supplementary Table S2. Images were acquired using a Nikon Ti Eclipse motorized inverted microscope with DIC, phase epifluorescence optics and Perfect Focus System (PFS). Equipped with a Nikon DS-Fil color CCD camera and NIS-Elements image acquisition software. Fluorescence images were acquired using a Zeiss LSM 710 Axio Observer confocal Z1 laser scanning microscope (as above). All images were taken using the same settings, and on the same day. The specific signal inside WMTs was quantified per area and normalized to the nonspecific signal outside of WMTs. Quantification of SMI-32, vGlut1 and $\mathrm{TH}$ immunoreactivity in the caudate were performed based on 6-10 fields per brain at $\times 20$ magnification (Image J). Fields were chosen randomly. Images were taken and analyzed blindly to tissue classifying information.

\section{Quantifications}

Quantifications were performed blinded to treatments. To reduce experimental error, comparisons were made within slides that were processed and analysed in parallel. Image series were analyzed with Image Pro Plus 6.3 (Media Cybernetics, Bethesda, MD, USA) or Fiji (Image J). An average value was calculated for each animal, followed by calculation of the average for the group. Data presented in percent of control cells when including different immunostaining events. Quantitation of the signal localized specifically to neurites was performed with Image $J$ as recently described [41]. Determination of neurite and axon length, number and length of collateral branches (longer than $15 \mu \mathrm{m}$ ) was done by tracing an axon including its collateral branches, starting from the cell body throughout, using the segmentation plugin for neurite tracer in Image J.

\section{Statistics}

Comparisons between two groups were performed by two-tailed ttest. Additional comparisons were performed by one-way ANOVA and Dunnett test for correction for multiple comparisons (Prism 7). Data presented as mean \pm SD or mean \pm SE, as indicated. Significant differences were considered with $P \leq 0.05$.

\section{Results}

Higher density of thinner axons in striatal WMTs of a-Syn tg mouse brains

To investigate a potential role for $\alpha$-Syn in axon integrity we analyzed the ultrastructure of cross-sectioned axons, localized within striatal WMTs, in coronal sections of A53T $\alpha$-Syn tg and control mouse brains [20]. We 
reasoned that the anatomical organization of the axons within the bundles and the relevance of the brain area to the disease could best fit our focus of investigation. The tissue block was set to contain the dorsal striatum, just underneath the corpus callosum, using the size of the lateral ventricle as a reference for tissue position (Fig. 1a,
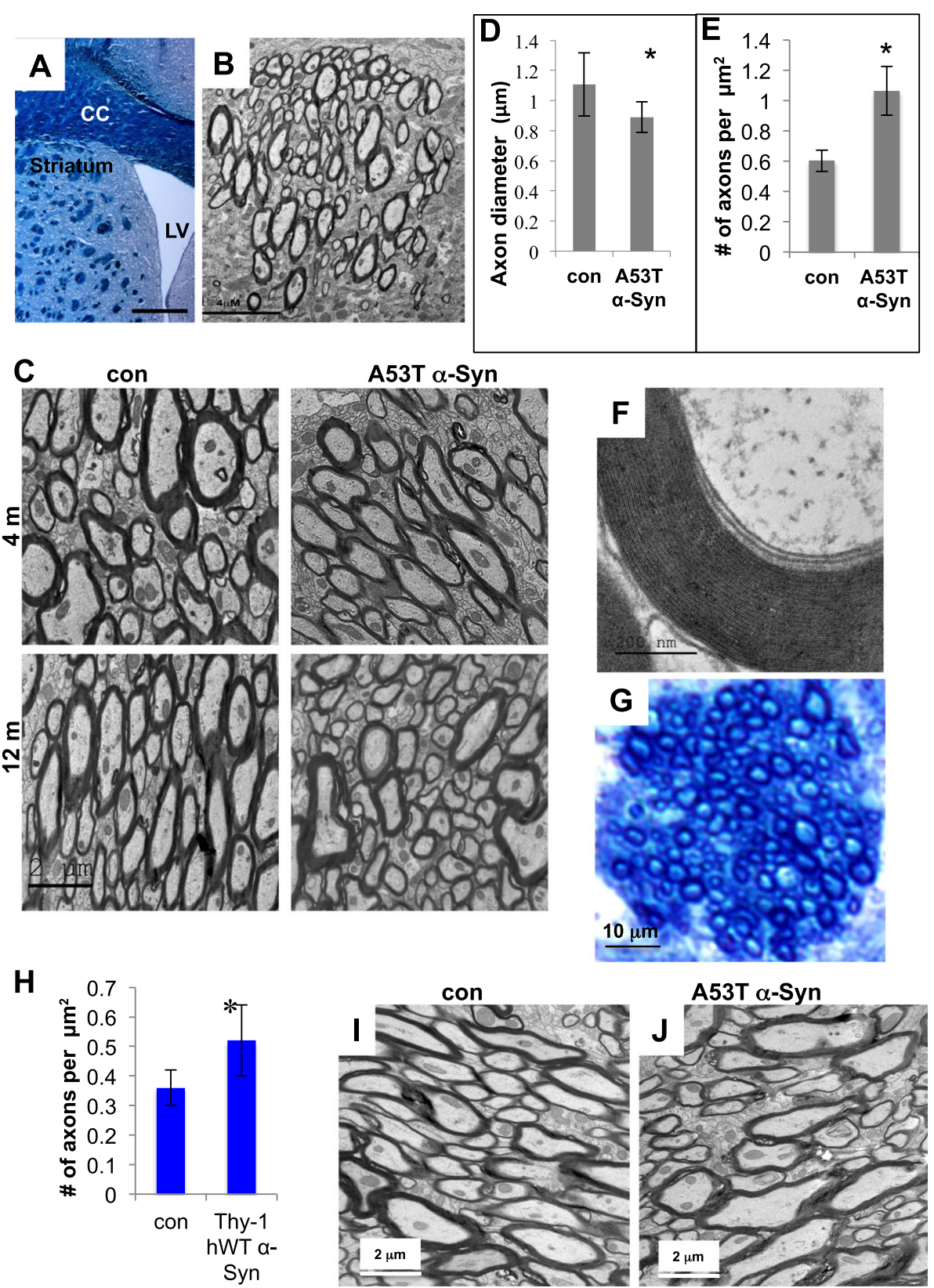

Fig. 1 Ultrastructure of cross-sectioned axons in white matter tracts (WMTs). a Lower magnification of a coronal mouse brain section, stained with Luxol Fast blue (Sigma-Aldrich), showing the striatum. CC, corpus callosum; LV, lateral ventricle; WMTs shown as dark spots over the lightly stained striatal grey matter. Bar $=1 \mathrm{~mm}$. b Cross section of a WMT in the dorsal striatum, consisting of myelinated axons. Image obtained by transmission electron microscope (TEM). Bar $=4 \mu \mathrm{m}$. c TEM images of coronal brain sections containing WMTs from A53T a-Syn and control mouse brains, at 4 months (healthy mice) or 12 months of age (symptomatic). Bar $=2 \mu \mathrm{m}$. $\mathbf{d}$ Bar graph showing the diameter (in $\mu \mathrm{m}$ ) of crosssectioned axons in WMTs. e. The number of axons per $\mu \mathrm{m}^{2}$ area of WMTs (axon density). Mean \pm SE $n=4$ brains, 5-8 WMTs per brain. $\mathbf{f}$ Intact myelin ultrastructure of a cross-sectioned axon in a WMT of 12 months old A53T a-Syn tg mouse brain. Bar $=200 \mathrm{~nm}$. g A semi-thick A53T a-Syn mouse brain section $(1 \mu \mathrm{m})$, stained with methylene blue (Sigma-Aldrich), showing cross-sectioned axons in a WMT. Bar $=20 \mu \mathrm{m}$. $\mathbf{h}$ Graph showing axon density in WMTs of Thy-1 hWT a-Syn and control mouse brains at 10-12 months of age. Determined in semi-thick sections (1 $\mu \mathrm{m})$ stained with methylene blue. Mean \pm SE of $n=4$ brains, 8-10 WMTs per brain. $\mathbf{i}$ and $\mathbf{j}$ TEM images showing sagittal brain sections across the axons in corpus callosum of 12-14 months old A53T and age-matched control (C57BL/6JOlaHsd) mouse brains 
b). Axon diameter and the density of axons were determined within WMTs of similar size $\left(\sim 1.5-4 \times 10^{-10} \mathrm{~m}^{2}\right)$ and similar location at 2-4 months of age, representing healthy, fully myelinated mouse brains [42] and at the age of 12-14 months, representing symptomatic mice [20, 22] (Fig. 1c-e). A significantly lower diameter was detected for axons of 12-14 months old A53T $\alpha$-Syn tg $(0.89 \pm 0.1 \mu \mathrm{m})$ than in age-matched control mouse brains $(1.1 \pm 0.2 \mu \mathrm{m})$. Mean \pm SE of $n=4$ brains, $8-10$ WMTs per brain; $P<0.01$, ttest. Surprisingly, the number of myelinated axons per $\mu \mathrm{m}^{2}$ within WMTs was significantly higher in the A53T $\alpha$-Syn $\operatorname{tg}(1.06 \pm 0.16)$ than in control brains $(0.60 \pm 0.07)$. Mean $\pm \mathrm{SE}$ of $n=4$ brains, 8-10 WMTs per brain; $P<0.05$, ttest. In accord with our recent report [23], no overt myelin ultrastructure or pathology was detected (Fig. 1f). That is, large axons, with a standard number and structure of lamellae were commonly detected in WMTs of the A53T $\alpha$-Syn brains. However, compared with the control brains, a higher number of thinner axons, which are only sparsely myelinated were detected in the A53T $\alpha$-Syn brain sections (Fig. 1c). Of note, differences in axon diameter or density between control and A53T $\alpha$-Syn tg brains at young, 2-4 months of age were not statistically significant.

Similar results, indicating a higher density of axons within striatal WMTs, were detected in a second $\alpha$-Syn $\operatorname{tg}$ mouse line, the Thy- 1 hWT $\alpha$-Syn mice $[24,25]$. Semi-thick brain sections $(1 \mu \mathrm{m})$ from 10 to 12 months old Thy-1 hWT $\alpha$-Syn and control, age-matched nontransgenic littermates, were stained with methylene blue for visualization of myelin sheath (Fig. 1g,h). Comparing between WMTs of similar size and similar location (as above), we determined $0.52 \pm 0.12$ and $0.38 \pm 0.06$ myelinated axons per $\mu \mathrm{m}^{2}$ in Thy-1 hWT $\alpha$-Syn and control mouse brains, respectively. Mean \pm SE of $n=4$ brains, $6-$ 8 WMTs per brain. $P<0.05$, ttest.

The EM blocks containing coronal brain sections positioned at dorsal striatum, including the corpus callosum, were cut one more time in a position corresponding to sagittal brain sections (Fig. 1i,j). The sections, across the axons in corpus callosum of 12-14 months old A53T $\alpha$ Syn and control mouse brains, revealed a high variability in axon diameter and axon density. No differences in the ultrastructure of axons were detected in the corpus callosum.

\section{Longer axons and collaterals in primary cultures of mouse neurons expressing a-Syn}

To investigate a potential involvement of $\alpha$-Syn in elongation and/or branching of axons we studied primary cultures of cortical neurons from $\alpha-\mathrm{Syn}^{-/-}$mouse brains. The cultures were transduced to express either human WT or A53T $\alpha$-Syn, or a synthetic K10,12E $\alpha$-Syn mutation generated by replacing two positively charged Lysine residues, within the KTKEGV repeat domain, with negatively charged Glutamic acid residues. In a previous study, this mutation was shown to interfere with $\alpha$-Syn binding to membrane phospholipids [43]. Control cells expressed a mock-GFP vector. Cells were fixed at 4 DIV and immunoreacted with antibodies against $\alpha$-Syn, $\alpha$-tubulin and the acidic phosphoinositide, PI4,5 $\mathrm{P}_{2}$. The average length of the primary axon in control cortical neurons, transduced with the mock virus (in $\mu \mathrm{m}$ ) was $108.50 \pm 29$.9. Significantly longer axons were measured for WT $\alpha$-Syn expressing $(150.43 \pm 28.6)$ and furthermore for A53T $\alpha$-Syn expressing neurons (175.97 \pm 23.8). Axon length in neurons expressing the K10,12E mutation $(121.2 \pm 31.8)$ was not different than in control cells. Mean \pm SE; $n>22$ cells; $P<0.05$, one way ANOVA (Fig. 2a,b).

A dramatic effect on the total length of collaterals, extending from the main axon, was observed. The total length of collaterals (per axon) was $\sim 6.5$ folds higher in WT $\alpha$-Syn and $\sim 10$ folds higher in A53T $\alpha$-Syn than control neurons. In contrast, the length of collaterals in neurons expressing K10,12E $\alpha$-Syn did not differ from control cells (Fig. 2c, mean \pm SE; $\mathrm{n}>22$ cells; * $P<0.05$; one way ANOVA).

Importantly, similar to A53T $\alpha$-Syn, expression of A30P $\alpha$-Syn in primary mouse cortical neurons resulted in longer axons and longer collaterals compared with WT $\alpha$-Syn expressing neurons (Supplementary Fig. S1E). Moreover, $\alpha$-Syn effects to enhance axon outgrowth were similarly detected in primary mouse hippocampal as well as mesencephalic neurons (Supplementary Fig. S1).

\section{Altered PI4,5 $\mathrm{P}_{2}$ levels in a-Syn expressing neurons}

Phosphoinositides are a group of acidic phospholipids and $\mathrm{PI} 4,5 \mathrm{P}_{2}$ is implicated in axonal growth $[13,18,19]$. Attempting to find out whether $\alpha$-Syn associations with membrane phospholipids and its preference for acidic phospholipids [44] may play a role in its effects to enhance axon outgrowth, we co-immunoreacted the primary cortical neurons with anti PI4,5 $\mathrm{P}_{2}$ ab (Fig. 2a). $\mathrm{PI}, 5 \mathrm{P}_{2}$ levels were determined per axon area $\left(\mu \mathrm{m}^{2}\right.$, Fig. $1 d)$ by ICC. Setting PI4,5P $\mathrm{P}_{2}$ levels in control axons at $100 \%$, we detected significant $\sim 118 \%$ and $\sim 135 \%$ higher PI4,5P $\mathrm{P}_{2}$ levels in WT and A53T $\alpha$-Syn expressing axons, respectively. The A30P mutation in $\alpha$-Syn similarly increased PI4,5P 2 levels over WT $\alpha$-Syn (Supplementary Fig. S1E). However, expression of K10,12E $\alpha$-Syn mutation had no detectable effects on PI4,5P 2 levels $(n=22-24$ cells, $P<0.05$, one-way ANOVA). $\alpha$ Syn expression in hippocampal neurons resulted in similar increases in axonal PI4,5 $\mathrm{P}_{2}$ levels. That is, PI4, 

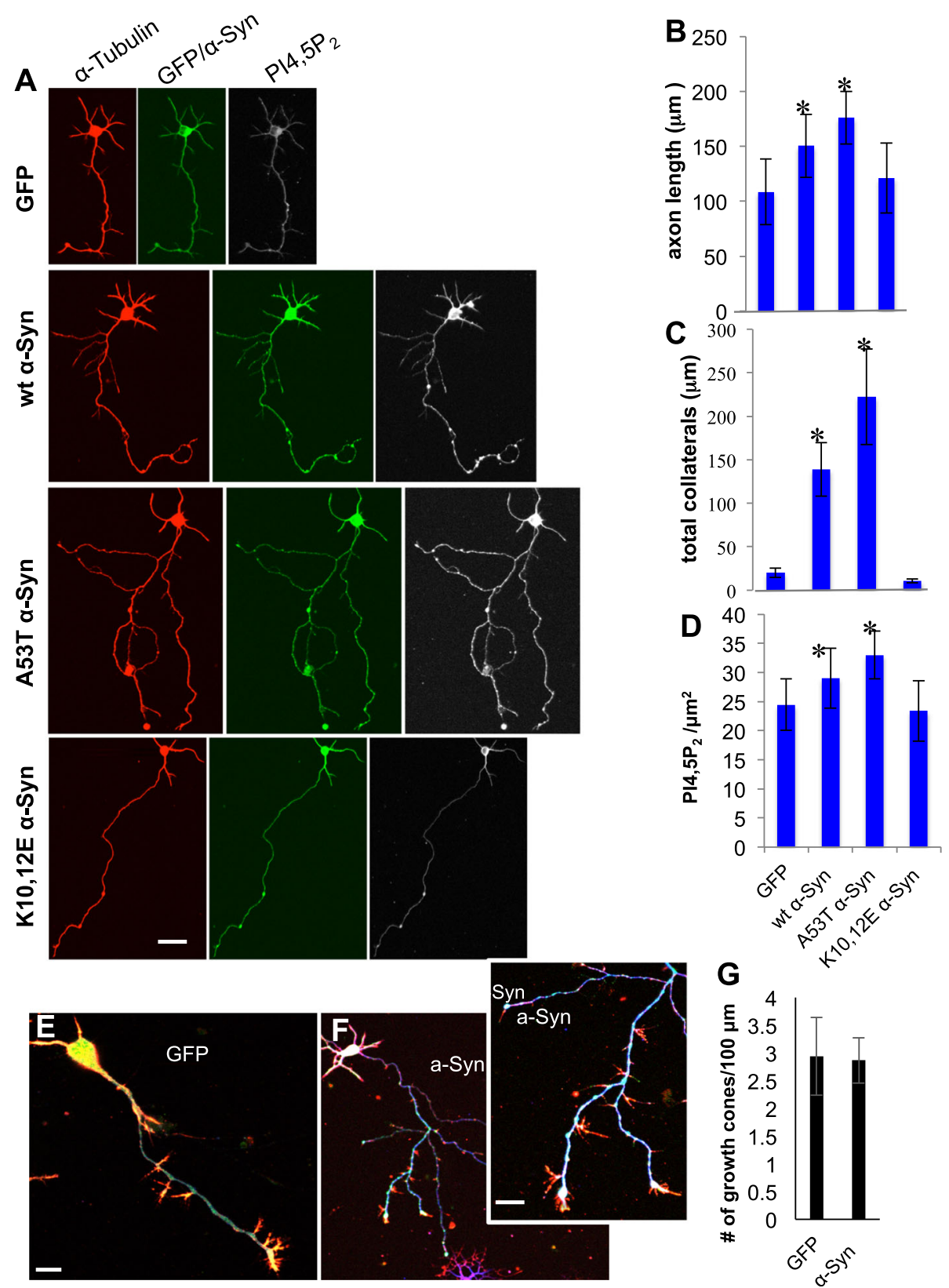

Fig. 2 Elongated axons and collaterals in primary cortical neurons expressing a-Syn associate with higher levels of phosphatidylinositol 4,5bisphosphate $\left(\mathrm{PI} 4,5 \mathrm{P}_{2}\right)$. a Primary cortical cultures from a-Syn ${ }^{-/-}$(C57BL/6JOlaHsd) mouse brains, virally transduced either with WT a-Syn, A53T aSyn, K10,12E a-Syn, or a mock-GFP vector. Cells were fixed at 4 DIV and immunoreacted with antibodies against a-Syn (MJFR1, green), a-tubulin (red) and PI4,5P (white). Direct fluorescence was captured for GFP (green). Bar $=25 \mu \mathrm{m}$. b Graph showing the average axon length (in $\mu \mathrm{m}$ ); $\mathbf{c}$ Total length of collaterals per axon (in $\mu \mathrm{m}$ ); and $\mathbf{d}$ PI4,5P 2 levels within the axon and its collaterals (per $\mu \mathrm{m}^{2}$ area) quantified by Fiji (Image J) program. Mean $\pm \mathrm{SE} ; n>22$ cells; ${ }^{*}, P<0.05$. e A primary cortical neuron as in (a), transduced with a mock-GFP (green); immunoreacted with anti GAP-43 (blue) and stained with rhodamine-phalloidin (red). Bar $=10 \mu \mathrm{m}$ F. A neuron as in (e) expressing WT a-Syn and immunoreacted with anti a-Syn (MJFR1, green) and anti a-tubulin (blue) abs, and stained with rhodamine-phalloidin (red). Shown an entire cell and a zoom on axon collaterals. Bar $=5 \mu \mathrm{m}$. No differences in number of growth cones per axon (in $\mu \mathrm{m}$ ) were detected. $\mathbf{g}$ Graph bar showing quantitation of growth cones per $\mu \mathrm{m}$ axon in WT a-Syn and GFP expressing neurons. Mean \pm SD of $n=12-15$ cells

$5 \mathrm{P}_{2}$ levels in hippocampal axons (per $\mu \mathrm{m}^{2}$ ) expressing WT or A53T $\alpha$-Syn were 122 and 131\% higher (respectively) than in axons expressing a mock virus, set at 100\% (Supplementary Fig. S1D).
a-Syn expression does not alter the number of growth cones per axon

The increases in axon density demonstrated in Fig. 1 could potentialy result from increases in the number of 
growth cones per $\mu \mathrm{m}$ axon. To assess growth cones, we co-immunoreacted cultured cortical neurons at 4 DIV, expressing either mock-GFP or WT $\alpha$-Syn, with an anti GAP-43 antibody, a marker for growth cones and phalloidin, a marker for filamentous actin (Fig. 2e). A parallel immunoreaction included anti $\alpha$-tubulin and phalloidin (Fig. 2f). Closely similar numbers of growth cones per $\mu \mathrm{m}$ axon were found for $\alpha$-Syn expressing $(2.85 \pm 1.0)$ and mock-GFP expressing cells $(2.93 \pm 1.7)$ using the different antibodies (Mean \pm SD, $n=12-15$ cells). Suggesting no effect for $\alpha$-Syn expression on the number of growth cones per axon (Fig. 2g).

\section{a-Syn regulates $\mathrm{PI}, 5 \mathrm{P}_{2}$ levels}

In a series of experiments, we assessed the associations of $\alpha$-Syn with PI4,5P $\mathrm{P}_{2}$ and the specificity of these associations. Silencing endogenous $\alpha$-Syn expression in SKmel 2 cells with shRNA resulted in $\sim 70 \%$ lower $\alpha$-Syn levels relative to control cells, transduced with a scrambled shRNA (set at 100\%; Fig. 3a). In accord, PI4,5P 2 levels, determined by FACS were $\sim 34 \%$ lower in shSNCA compared with shCntrl expressing cells (Fig. $3 \mathrm{~b}, \mathrm{c})$. Mean \pm SE; $n=4000$ cells; $P<0.05$, ttest. PI $4,5 \mathrm{P}_{2}$ levels were next determined by FACS in HEK $293 \mathrm{~T}$ cells, transfected to express $\alpha$-Syn (Fig. 3d). A significantly higher PI4,5P $\mathrm{P}_{2}$ signal was detected in WT $\alpha$-Syn $(140.7 \pm 15.5 \%)$ and A53T $\alpha$-Syn $(211.9 \pm 33.2 \%)$ expressing cells than in control cells (set at $100 \%)$. Mean \pm SE, $P<0.05$, one way ANOVA. However, PI4,5 $\mathrm{P}_{2}$ levels in cells expressing the K10,12E $\alpha$-Syn mutation were not different than control cells (Fig. 3d).

Similar results were obtained using a PH-PLC81GFP molecular indicator of $\mathrm{PI} 4,5 \mathrm{P}_{2}$ levels. HeLa cells were transfected to express WT, A53T, K10,12E $\alpha$ Syn or a mock vector, together with a plasmid expressing PH-PLC81-GFP. Cells were incubated with 647-concanavalin A (ConA) to mark the plasma membrane (Fig. 3e,f). The relative fluorescence intensity of PH-PLC 1 -GFP in plasma membrane to cytosol was set at $100 \%$ for the mock plasmid expressing cells. Significant $158.9 \pm 37 \%$ and $169.0 \pm 38 \%$ higher values were detected for WT and A53T $\alpha$-Syn expressing cells, respectively. No effect for the K10,12E $\alpha$-Syn mutation on PH-PLC $1-$ GFP signal was detected. Mean \pm SE of 3 independent experiments; $n=$ 15-25 cells in each experiment, $p<0.05$, one-way ANOVA.

To find out if endogenous mouse $\alpha$-Syn similarly enhances PI4,5 $\mathrm{P}_{2}$ levels in vivo, we immunoreacted paraffin embedded, coronal brain sections from 2 months old $\alpha$ $\mathrm{Syn}^{-1-}$ (C57BL/6JOlaHsd) and age-matched WT C57BL/ 6 mice with anti PI4,5P . We found a significantly lower signal in $\alpha-$ Syn $^{-1-}(61.8 \%)$ than control WT mice (set at $100 \%$, Fig. 3 g). $P<0.01$, ttest. $N=5$ mouse brains in each genotype. Importantly, PI4,5 $\mathrm{P}_{2}$ signal appeared in the nuclei and on the PM surrounding the cell body, supporting the specificity of the antibody-detected signal. The effect of mouse endogenous $\alpha$-Syn on PI4,5 $\mathrm{P}_{2}$ levels was next tested in primary hippocampal neurons at 14 DIV prepared in parallel from WT C57BL/6 and $\alpha$ $\mathrm{Syn}^{-/-}$mouse brains (Fig. 3h). Cultured neurons were co-immunoreacted with anti $\mathrm{PI} 4,5 \mathrm{P}_{2}$ and anti neurofilament (NF-200) antibodies. Normalizing the signal obtained for PI $4,5 \mathrm{P}_{2}$ to the signal detected for NF-200, we detected a significant lower PI4,5 $\mathrm{P}_{2}$ signal in hippocampal neurons from $\alpha-\mathrm{Syn}^{-1-}(\sim 66 \%)$ than C57BL/6 mouse brains (set at $100 \%$ ). Mean \pm SD, $n=5$ fields, consisting of $>10$ cells; $P<0.05$, ttest.

To confirm the specificity of the PI4,5 $\mathrm{P}_{2}$ signal we detect using anti $\mathrm{PI} 4,5 \mathrm{P}_{2}$ ab in cortical neurons, we determined PI4,5 $\mathrm{P}_{2}$ signal depletion following phospholipase $C$ (PLC) activation. Primary cortical neurons from $\alpha$ $\mathrm{Syn}^{-/-}$(C57BL/6JOlaHsd) mouse brains were treated with carbachol (1 $\mathrm{mM}$ at 5 DIV), a muscarinic agonist that activates PLC [45]. Control cells were conditioned and treated in parallel but without the drug. Cells were fixed and immunoreacted with anti $\mathrm{PI} 4,5 \mathrm{P}_{2}$ ab (Supplementary Fig. S2A). PI4,5 $\mathrm{P}_{2}$ signal in the carbachol treated neurons $(25 \%)$ was dramatically lower than the signal detected in control neurons, treated with DMSO solvent (set at $100 \% ; P<0.01$, ttest). Importantly, in images captured at higher magnification, the loss of PI4, $5 \mathrm{P}_{2}$ signal is clearly detected on the PM of the cell body and throughout the axon, supporting specificity of the detected PI4,5P 2 signal (Supplementary Fig. S2B). Similar results, showing loss of PI4, $5 \mathrm{P}_{2}$ signal following PLC activation in primary cortical neurons were obtained following activation of the muscarinic receptors with acetylcholine $(10 \mu \mathrm{M})$ and pilocarpine $(9.6 \mu \mathrm{M})$.

As an additional approach to study PI4,5 $\mathrm{P}_{2}$ signal specificity, we expressed the rapamycin-induced translocatable CF-PIPK construct, which consists of an active PIPKI $\gamma$, a flourosence CFP and a FKBP domain [33]. In HEK293T cells, CF-PIPK fluorescence was largely in the cytosol and moved to the PM with the addition of rapamycin. In accord with the localization of CF-PIPK, the detectable PI4,5 $\mathrm{P}_{2}$ signal was intracellular or on the PM, respectively (Supplementary Fig. S2C).

\section{a-Syn effect to elongate the main axon and collaterals requires $\mathrm{PI}_{4}, 5 \mathrm{P}_{2}$}

To investigate the potential involvement of PI4,5 $\mathrm{P}_{2}$ in $\alpha$-Syn-dependent axonal outgrowth, we tested the effects of synaptojanin-1 ( $\mathrm{Sj}-1)$, a PI4,5 $\mathrm{P}_{2}$ 5-Phosphatase or PIPKI $\gamma$ to alter PI4,5P $\mathrm{P}_{2}$ levels in HEK $293 \mathrm{~T}$ cells expressing $\alpha$-Syn (Fig. 4a,b). In cells co-expressing $\alpha$ Syn and $\mathrm{Sj}-1$ the increase in $\mathrm{PI} 4,5 \mathrm{P}_{2}$ levels, associated 

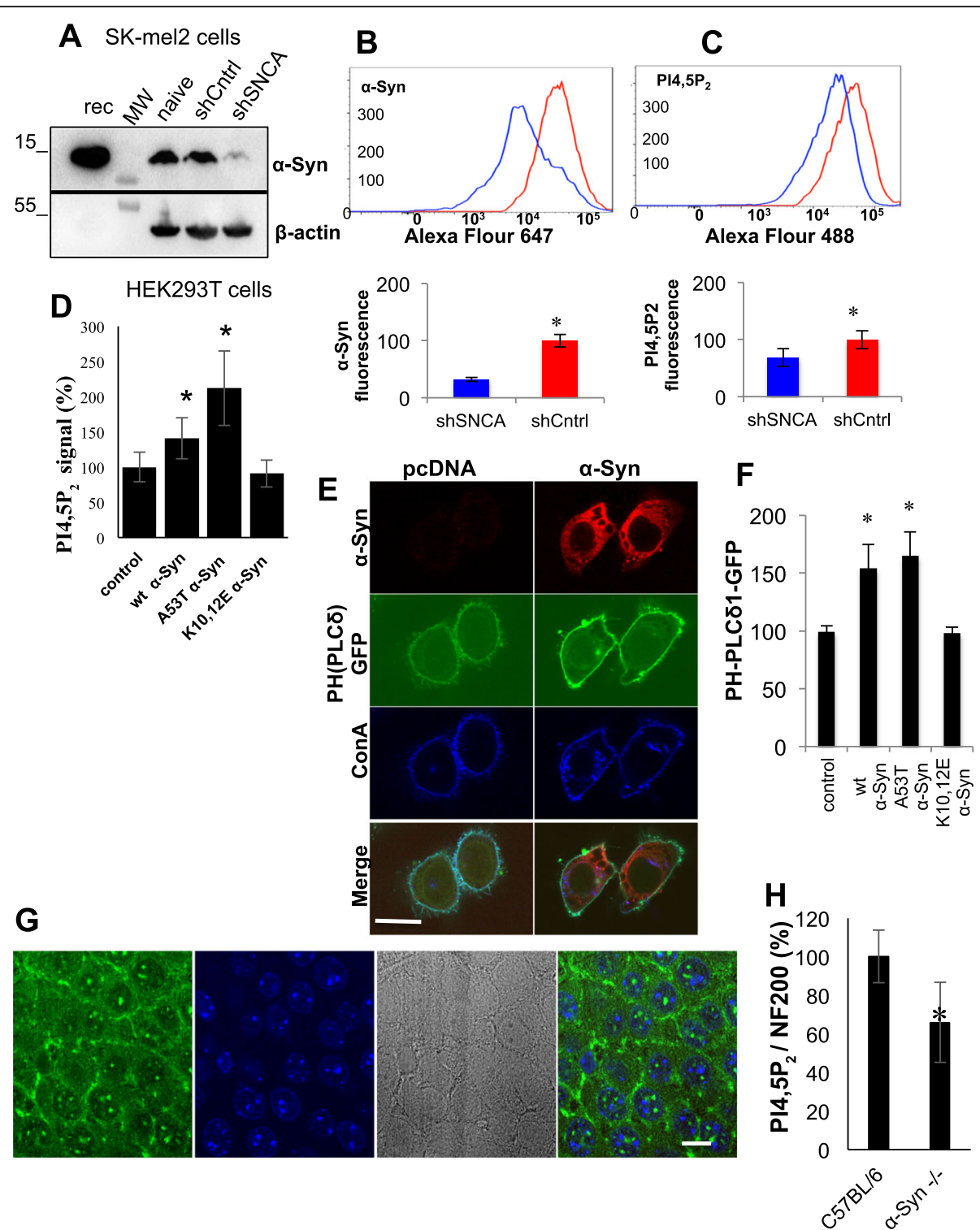

Fig. 3 a-Syn expression regulates PI4,5P 2 levels. a SK-mel2 cells transduced with viral particles expressing either sh-SNCA or a control (sh-Cntrl). 3-7 days post transduction, samples of lysed cells $(80 \mu \mathrm{g}$ protein) were analyzed by Western blotting for a-Syn expression using MJFR1 antibody. b SK-mel2 cells transduced as in (a) and analyzed by FACS for a-Syn, using anti a-Syn antibody MJFR1; and c using anti PI4,5P 2 antibody. Mean \pm SE, $n=4000$ cells; ${ }^{*}, P<0.05$, ttest. d HEK 293 T cells were transfected either with WT a-Syn, A53T or K10,12E a-Syn mutations, or mock transfected. $48 \mathrm{~h}$ post transfection, PI4,5P levels were determined by FACS, using anti PI4,5P 2 antibody. Cells were gated based on positive signal for a-Syn detected by MJFR1 antibody. Mean \pm SE, $n>3000$ cells; ${ }^{*}, P<0.05$, one way ANOVA. e HeLa cells, co-transfected with WT a-Syn and PHPLC81-GFP. Control cells transfected with the mock plasmid together with PH-PLC81-GFP. Cells were incubated with Alexa-647 Concanavalin (Con) A for visualization of plasma membrane (PM) and processed for ICC with anti a-Syn antibody, C20. Showing the co-localization of PHPLC81-GFP and 647-ConA signals (direct fluorescence). Bar $=10 \mu \mathrm{m}$. $\mathbf{f}$ Calculated plasma membrane to cytosol ratio of the PH-PLC81-GFP signal in HeLa cells, co-expressing the indicated constructs. Mean \pm SE of $n=15-25$ cells. ${ }^{*}, p<0.05$, one way ANOVA. $\mathbf{g}$ High magnification of paraffin embedded mouse brain section containing the hippocampus, analyzed by $\mathrm{IHC}$ and immunoreacted with anti PI4,5P $\mathrm{ab}$ (green). Section stained with DAPI (blue). Nomarski image (gray) shown to demonstrate PI4,5P2 signal on PM. Bar $=10 \mu \mathrm{M}$. h Primary cortical neurons from WT C57BL/6 or a-Syn -/- (C57BL/6JOlaHsd) at 14 DIV. Cultured neurons analyzed by ICC and immunoreacted with anti NF-200 and anti PI4,5P 2 abs. Bar graph shows signal ratio of PI4,5P to NF200. Mean \pm SD, $n=5$ fields, consisting of $>10$ neuronal cell bodies each; ${ }^{*}, P<0.05, t$-test

with its expression (e.g., 132\% increase), was denied and PI4,5 $\mathrm{P}_{2}$ levels were below the levels of control cells, expressing the mock plasmid. In accord, a dramatic $~ 700 \%$ increase in PI4,5P $\mathrm{P}_{2}$ levels was detected with PIPKIY expression and an additive effect of $20 \%$ was observed in cells co-expressing $\alpha$-Syn and PIPKI $\gamma$ (Fig. 4b). Mean \pm SD of $n>3000$ cells; $P<$ 0.05 , one-way ANOVA. 

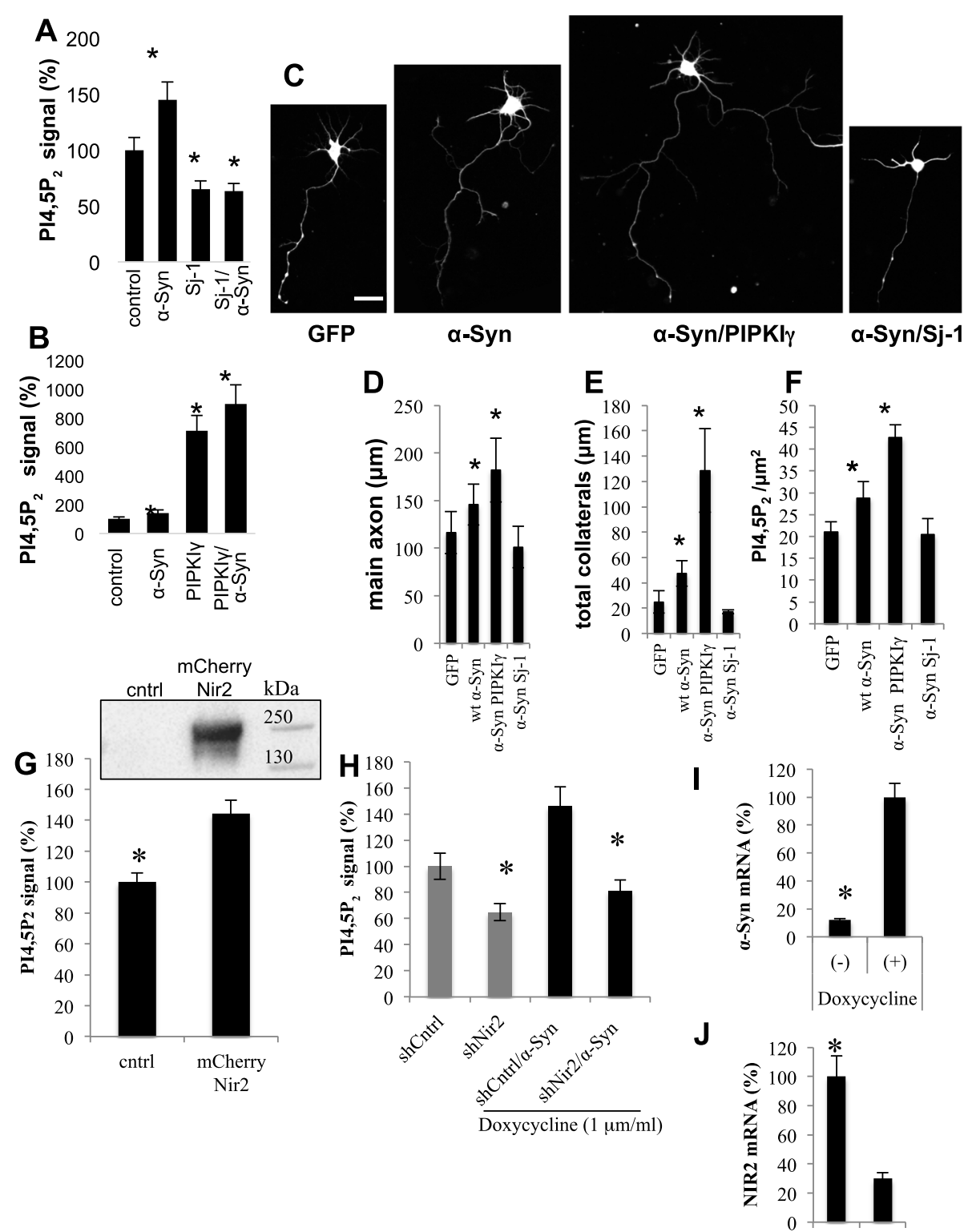

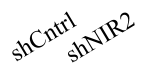

Fig. 4 a-Syn effect to elongate axons and collaterals is mediated through PI4,5P 2 a PI4,5P levels determined by FACS, in HEK 293 T cells, following $48 \mathrm{~h}$ from cell transfection with a-Syn and/or Sj-1 phosphatase, as indicated. Mean \pm SD of two independent experiments, $\mathrm{n}>3000$ cells in each treatment; $P<0.05$, one-way ANOVA. b PI4,5P 2 levels determined by FACS in HEK 293 T cells transfected with a-Syn and/or PIPKIy as indicated. Mean \pm SD of two independent experiments, $n>3000$ cells in each treatment; $P<0.05$, one-way ANOVA. c Primary cortical cultures from a-Syn ${ }^{-1}$ mouse brains, electroporated at day of preparation to co-express WT a-Syn together either with PIPKly-GFP, Sj-1-GFP or mock-GFP expressing vectors (as indicated). Cultures were fixed and immunoreacted with anti a-Syn MJFR1 ab and a-tubulin. GFP signal was captured by direct fluorescence. a-tubulin signal is shown. Bar $=25 \mu \mathrm{m}$. $\mathbf{d}$ The average length of axons (in $\mu \mathrm{m}$ ). e Total length of collaterals per axon (in $\mu \mathrm{m}$ ); and $\mathbf{f} \mathrm{P} \mid 4,5 \mathrm{P}_{2}$ levels within the axon and its collaterals (per axon area) quantified by Fiji program. Mean $\pm \mathrm{SE} ; n>25$ cells; ${ }^{*}, P<0.05$ one-way ANOVA. g HEK 293 T cells transfected to express mCherry-Nir2 or mock transfected (cntrl). Western blot showing mCherry-Nir2 signal detected with anti Nir2 ab (Abcam). PI4,5P levels determined by FACS. Mean $\pm \mathrm{SE}, \mathrm{n}>3000$ cells; ${ }^{*}, P<0.05$, ttest. $\mathbf{h}$ Tet-on inducible SH-SY5Y cells for inducible a-Syn expression were infected with viral vectors expressing either shNIR2 or shCntrl (Mission, Sigma-Aldrich). a-Syn expression induced with doxycycline $(1 \mu \mathrm{M} / \mathrm{ml})$ or non-induced. PI4,5P levels determined by FACS. Mean \pm SD of $n=3$ different experiments, $>3000$ cells in each treatment. i Quantitative PCR (qPCR) detection of a-Syn following its induced expression in SH-SY5Y cells without and with the addition of doxycycline for $72 \mathrm{~h}$. a-Syn mRNA levels normalized to the levels of G6PD gene detected in the same sample. $\mathbf{j}$ Quantitative detection of NIR2 expression by qPCR in these cells 
We next co-expressed $\alpha$-Syn either with Sj-1or PIPKI $\gamma$ in primary cortical neurons from $\alpha-\mathrm{Syn}^{-/-}$mouse brains by electroporation. Control neurons expressed WT $\alpha-$ Syn together with a mock plasmid or a GFP expressing vector. Cultures were fixed and immunoreacted with antibodies against $\alpha$-Syn, $\alpha$-tubulin and PI4,5 $\mathrm{P}_{2}$. The expression of $\mathrm{Sj}-1$, PIPKI $\gamma$ and GFP were visualized directly based on their GFP tag. Similar to the results above (Fig. 2), longer axons and longer collaterals were measured for $\alpha$-Syn expressing cells (Fig. 4c-e). Specifically, the length of the main axon (in $\mu \mathrm{m}$ ) was $116.5 \pm 22.1$ in control cells and $145.7 \pm 21.7$ in WT $\alpha$-Syn expressing cells. Co-expression of WT $\alpha$-Syn together with PIPKI $\gamma$ further increased axon length $(182.1 \pm 33.6)$ and coexpression of WT $\alpha$-Syn together with $\mathrm{Sj}-1$, eliminated the elongative effect of $\alpha$-Syn $(101.0 \pm 21.8)$ with a mean value that is lower than control cells expressing the mock-GFP plasmid (Fig. 4c-d). The total length of collaterals per axon in WT $\alpha$-Syn expressing cells $(47.1 \pm$ $6.7 \mu \mathrm{m})$ was longer than control cells $(24.8 \pm 7.9 \mu \mathrm{m})$. Further increase in length of collaterals was observed with PIPKI $\gamma(128.6 \pm 19.3 \mu \mathrm{m})$ yet, $\alpha$-Syn effect to increase the length of collaterals was eliminated when coexpressed with $\mathrm{Sj}-1(17.1 \pm 8.1 \mu \mathrm{m}$; Fig. 4c, e, mean $\pm \mathrm{SD}$ of $n>20$ cells, * $P<0.05$; one way ANOVA).

Quantifying PI4,5 $\mathrm{P}_{2}$ levels in the axons, we found a significant increase with WT $\alpha$-Syn expression $(\sim 128 \%)$ and furthermore in cells expressing $\alpha$-Syn and PIPKI $\gamma$ $(\sim 205 \%)$. However, PI4,5P 2 levels in axons expressing $\alpha$ Syn and Sj-1 $(\sim 98 \%)$ were not different than control cells (100\%; Fig. 4f). Similar results, demonstrating the importance of PI4,5P $\mathrm{P}_{2}$ levels for $\alpha$-Syn-mediated elongation of axons and collaterals were obtained in primary mesencephalic neurons (Supplementary Fig. S1E-G). Based on these findings we conclude that the mechanism through which $\alpha$-Syn acts to elongate the axons is dependent on PI4,5 $\mathrm{P}_{2}$.

\section{The regulatory role of $\mathrm{a}-\mathrm{Syn}$ on $\mathrm{PI}, 5 \mathrm{P}_{2}$ levels is Nir2- dependent}

To test the mechanism through which $\alpha$-Syn increases cellular PI4,5P $\mathrm{P}_{2}$ levels, we tested the potential involvement of Nir2-expression. HEK293T cells were transfected to express mCherry-NIR2 or a mock (control) plasmid. $72 \mathrm{~h}$ post DNA transfection, $\mathrm{PI} 4,5 \mathrm{P}_{2}$ levels were determined by FACS. In line with a previous report [28], over-expressing mCherry-Nir2 in HEK $293 \mathrm{~T}$ cells increased PI4,5 $\mathrm{P}_{2}$ levels (Fig. 4g). To find out whether Nir2 expression is required for $\alpha$-Syn-mediated increases in PI4,5P $\mathrm{P}_{2}$ levels, we utilized SH-SY5Y cells, that inducibly express $\alpha$-Syn under a Tet-On control [46]. Cells were infected to silence NIR2 expression using a viral vector expressing shNIR2. Control cells were infected with shCntrl. Five days post infection, doxycycline
$(1 \mu \mathrm{M})$ was added to the cells to activate $\alpha$-Syn expression. PI $4,5 \mathrm{P}_{2}$ levels were determined by FACS following 3 days of incubation with doxycycline. The efficacy of shNIR2 to silence NIR2 expression was tested by qPCR and the levels were found to be $70 \%$ lower than in cells infected with the scrambled shRNA (set at 100\%, Fig. 4 j). $\alpha$-Syn levels of expression were $\sim 25$ folds higher with doxycycline (Fig. 4i). The results show that doxycyclin enhanced $\alpha$-Syn expression resulted $\sim 146 \%$ higher $\mathrm{PI}, 5 \mathrm{P}_{2}$ signal. However, the effect of doxycxline induced $\alpha$-Syn-expression on PI $4,5 \mathrm{P}_{2}$ signal was abolished when cells were infected to silence NIR2 expression (Fig. 4h, mean \pm SD of $n=3$ different experiments; $n=>3000$ cells in each treatment).

\section{Higher PI4,5 $\mathrm{P}_{2}$ levels in striatal WMTs of a-Syn tg mouse lines}

To draw a line between the findings in mouse brains, showing a higher density of axons within WMTs and the findings in primary neurons, showing an effect for $\alpha$ Syn to enhance axon outgrowth, we next determined PI4,5P $\mathrm{P}_{2}$ levels in striatal WMTs of $\alpha$-Syn tg and control brains. Paraffin embedded brain sections of healthy young and symptomatic old mice of two mouse models, the A53T $\alpha$-Syn and the Thy-1 hWT $\alpha$-Syn mice were analyzed by immunohistochemistry (IHC). The respective age and genotype-matched control mice were analyzed in parallel (see methods). The position of the sections was set as above (Fig. 1a). Brain sections were co-immunoreacted with PI4,5P $\mathrm{P}_{2}$ and NF-200 antibodies (Fig. 5a). PI4,5P levels were normalized to NF-200 signal, obtained within WMTs (per area). Setting PI4,5 $\mathrm{P}_{2}$ to NF-200 ratio of age and genotype- matched control mouse brains at $100 \%$, we detected $\sim 109 \%$ and significant $\sim 120 \%$ higher ratio in $2-4$ and $12-14$ months-old A53T $\alpha$-Syn mouse brains, respectively. Similar results, showing $\sim 107 \%$ and significant $\sim 115 \%$ higher ratio were detected in WMTs of 2-4 and 10 months-old Thy1 hWT $\alpha$-Syn mouse brains, respectively (Fig. 5b; mean \pm SE of $n=4$ brains; $P<0.05$, one-way ANOVA). In a control experiment, PI4,5 $\mathrm{P}_{2}$ to NF-200 signal ratio was determined in WMTs of 12 months-old 5XFAD mice, modeling Alzheimer's disease. Importantly, in contrast to the PD mouse models, the results show a significant lower $(\sim 70 \%)$ ratio in WMTs of old 5XFAD mice than in control brains (100\%) [27]. Mean \pm SE of $n=4$ brains; $P<0.05$. Together, specific higher PI4,5P $\mathrm{P}_{2}$ levels per axon were detected in striatal WMTs of old, symptomatic, $\alpha$-Syn tg mouse lines.

\section{Evidence for axonal injury within WMTs of a-Syn tg mouse brains}

To find out whether the effects of $\alpha$-Syn to increase axon density within WMTs are associated with its toxicity, we 
A
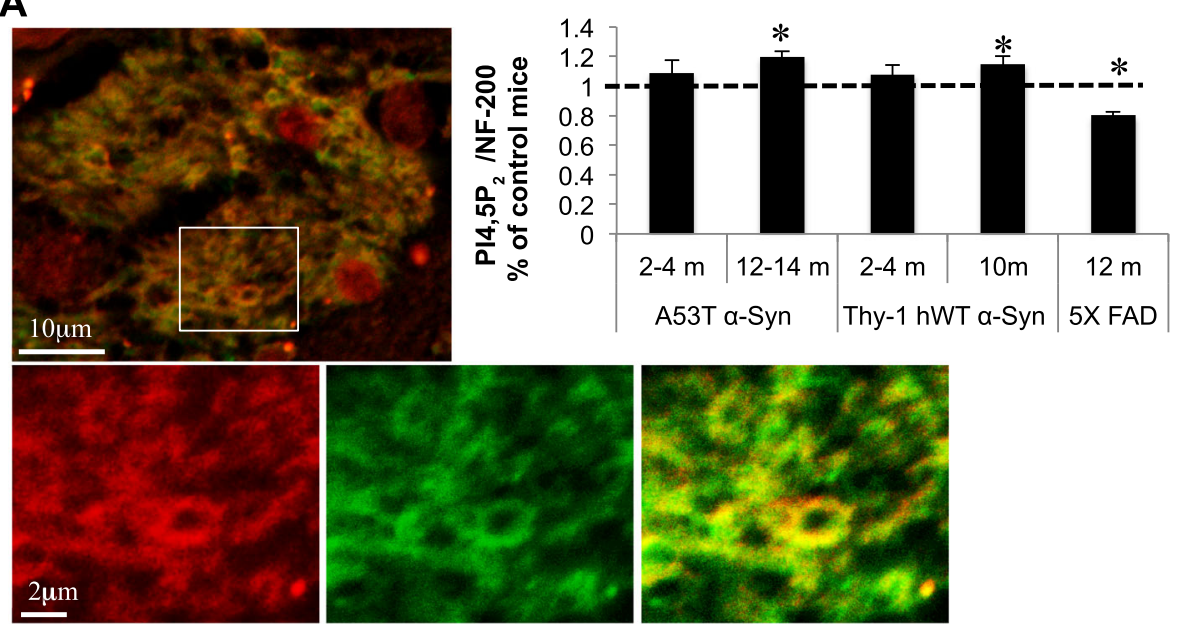

PI4,5P

NF-200

merge

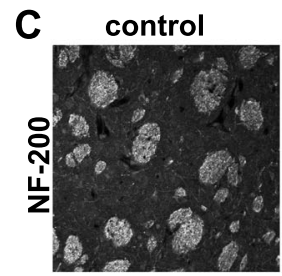

A53T $\alpha-S y n$
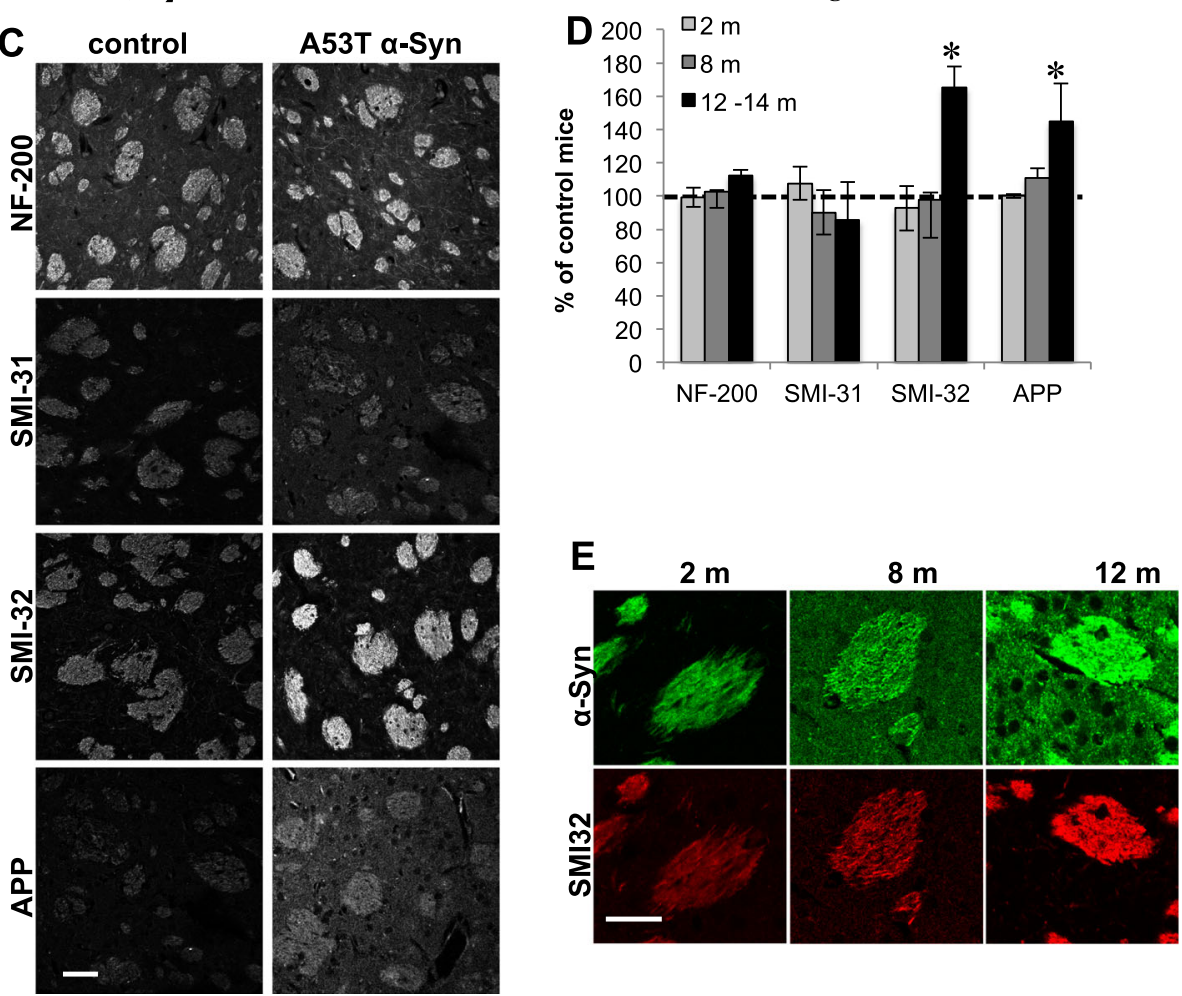

Fig. 5 Differences in WMTs between a-Syn transgenic and control mouse brains. a Paraffin embedded coronal brain section ( $6 \mu \mathrm{m})$ from A53T aSyn tg mouse, immunoreacted with anti NF-200 (green) and anti PI4,5P 2 (red) antibodies. Showing a WMT and the localization of the immunoreactivity to axon membrane. $\mathbf{b}$ Graph showing the immunoreactive signal ratio obtained for PI4,5P 2 and NF-200 within WMTs (per area) for A53T a-Syn or Thy-1 hWT a-Syn tg mouse models, presented as percent of age- and genotype- matched control mice set at 100\% (represinted by a vertical line). Mean $\pm \mathrm{SE}, n=4$ brains, ${ }^{*}, p<0.05$, one-way ANOVA. c Paraffin embedded coronal brain sections ( $\left.6 \mu \mathrm{m}\right)$ of A53T aSyn and control (a-Syn ${ }^{-1-}, \mathrm{C} 57 \mathrm{BL} / 6 \mathrm{JOlaHsd}$ ) mouse brains at 12 months of age, containing the dorsal striatum, immunoreacted either with antibodies against axonal markers SMI-32, SMI-31 and NF200 or anti APP antibody, a marker for axonal damage. Bar =50 $\mu \mathrm{m}$. $\mathbf{d}$ Quantification of the immunoreactivity obtained as in (c) in WMTs of A53T a-Syn tg and control (a-Syn ${ }^{-1-}$, C57BL/6JOlaHsd) mouse brains, at 2, 8 and 12-14 months of age. Vertical line represents age-matched control mice, set at 100\% for each of the tested antibodies. Mean \pm SE; $n=5$ mouse brain. ${ }^{*}$, $P<0.05$, one-way ANOVA. e Consecutive brain sections (as in $\mathbf{c}$ and $\mathbf{d}$ ) co-immunoreacted with syn303 anti a-Syn and anti SMI-32

antibodies. Bar $=20 \mu \mathrm{M}$ 
analyzed brain sections of A53T $\alpha$-Syn at 2, 8 and 12-14 months, and age-matched control mice by IHC. Brain sections were immunoreacted with an anti SMI-32 antibody, which recognizes the non-phosphorylated epitopes on the neurofilament proteins and known for its immunoreactivity with corticostriatal axons [47]. In addition, the sections were tested for SMI-31 immunoreactivity, which recognizes phosphorylated neurofilament. Consecutive brain sections were immunoreacted with an anti amyloid precursor protein (APP) antibody, as a marker for axonal injury [48]. The signal obtained within WMTs for each of these markers, in each of the tested age groups, was set at $100 \%$ for control mice. No differences were detected up to 8 months of age (Fig. 5d). In line with evidence for increases in axonal density within WMTs (Fig. 1), we detected a significant $165 \pm 18 \%$ higher SMI-32 immunoreactive signal in the $\alpha$-Syn tg mouse brains. Interestingly, the significantly $144 \pm 17 \%$ higher APP signal, detected in WMTs of 12-14 months old A53T $\alpha$-Syn mouse brains, indicates the occurrence of axonal damage (Fig. $5 \mathrm{c}$,d; mean \pm SD of $n=5$ mouse brains). In accord with the occurrence of axonal damage, we detected an age-dependent increase in $\alpha$-Syn immunoreactivity, determined with syn303 antibody, within SMI-32-positive striatal WMTs and also in striatal matrix (Fig. 5e).

\section{Plasticity of corticostriatal WMTs of human brains at early stages of PD}

To study the corticostriatal glutamatergic connections in PD brains, we determined SMI-32 signal in caudal WMTs and Vesicular glutamate transporter 1 (vGluT1) signal in corticostriatal terminals, at early PD (unified stages IIa and IIb [3]) and advanced PD (Braak stages 5$6[2])$. We reasoned that if glutamatergic plasticity indeed occurs in PD, then it is more likely to be detected at early rather than advanced disease stages. The results show a significant $135 \pm 24.8 \%$ higher SMI-32 signal in caudal WMTs of early PD cases $(n=5)$ compared with control brains $(n=7)$. Mean \pm SD; $P=0.03$, ttest (Fig. 6a). In contrast, a dramatic $46.9 \pm 38.1 \%$ lower SMI-32 signal was detected in advanced-PD cases $(n=5)$ compared with control brains $(n=7)$. Mean \pm SD; $P=0.01$, ttest (Fig. 6b,c). In accord, vGluT1 signal was considerably $283 \pm 87 \%$ higher in early PD $(n=5, P=0.007$, ttest $)$ and $67.4 \pm 32.8 \%$ lower in advanced $\operatorname{PD}(n=5, P=0.05$, ttest $)$ compared with control brains $(n=7$; Fig. $6 \mathrm{a}, \mathrm{b}$ and supplementary Fig. S3).

$\mathrm{TH}$ immunoreactivity was similarly determined in the caudate to test dopaminergic synapses in these human brains. TH signal was lower $(61.9 \pm 8.6 \%)$ in early PD and considerably lower $(16.5 \pm 9.7 \%)$ in the tested advanced PD cases $(P<0.05$, ttest; Fig. 6a,b and supplementary Fig. S3).
To find out whether SMI-32 immunoreactivity within WMTs correlates with vGluT1 immunoreactivity at corticostriatal terminals, we co-immunoreacted PD and control brain sections with SMI-32 and vGluT1 antibodies. A strong positive correlation between SMI-32 and vGluT1 signals (Pearson's $r$ value $=0.83$ ) was detected in the caudate of PD brains $(n=10)$. However, no correlation could be detected for the control brains (Pearson's $r$ value $-0.21 ; n=7$ ). The results therefore suggest that at early $\mathrm{PD}$, increases in glutamatergic axons within WMTs correlate with increases in glutamatergic terminals in the caudal matrix. However, with progression of disease, both, glutamatergic axons and terminals are degenerated (Fig. 6d).

Together, the analysis in human brains at early stages of PD validate the occurrence of corticostriatal plasticity within WMTs, localized to the caudate and the findings indicating higher density of SMI-32-positive glutamatergic axons in WMTs of $\alpha$-Syn tg mouse brains.

Evidence for $\alpha$-Syn pathology was commonly detected within caudal WMTs of advanced PD brains. $\alpha$-Syn pathology, detected in cross-sectioned axons within WMTs, consists mostly of Lewy neurites and observed as $\alpha$-Syn positive granulated signal. The densely hematoxylinstained glia cells within WMTs were devoided of Lewy pathology (Fig. 6e). Importantly, similar to the finding in the $\alpha$-Syn tg mouse brains (Fig. 5e) pathogenic forms of $\alpha$-Syn protein, detected with an anti filament $\alpha$-Syn antibody [49] were abundantly detected within WMTs and matrix early in PD, side by side with the increase in SMI32 immunoreactivity (Fig. 6f,g). Further increases in pathogenic $\alpha$-Syn were detected at advanced PD, however, these were accompanied with degeneration and loss of SMI-32 immunoreactive axons (Fig. 6f,g). Finally, we assessed the diameter of axons within WMTs of early PD and control cases. A high degree of variability in axon diameter within a specific WMT $(0.09-6.8 \mu \mathrm{m})$ was detected. We reasoned that the high variability in axon diameter between WMTs within the same brain section denies meaningful comparisons between the groups.

\section{The mouse model partly recapitulates the human disease}

We thought to assess the degree in which the mouse model recapitulates alterations in dopaminergic and glutamatergic terminals, and the severity of disease. In line with the original description of this A53T $\alpha$-Syn tg mouse line [20] TH-immunoreactivity detected by IHC, appeared highly similar between 12 and 14 months old A53T and age-matched control mice (Fig. 7a). No differences in TH-immunoreactivity were detected in the $\mathrm{SNc}$ (Fig. 7b), WMTs or striatum (Fig. 7c).

The expression levels of $\mathrm{TH}$, dopamine transporter (DAT) and synaptophysin, a marker for synaptic terminals, were next determined by a quantitative Western 

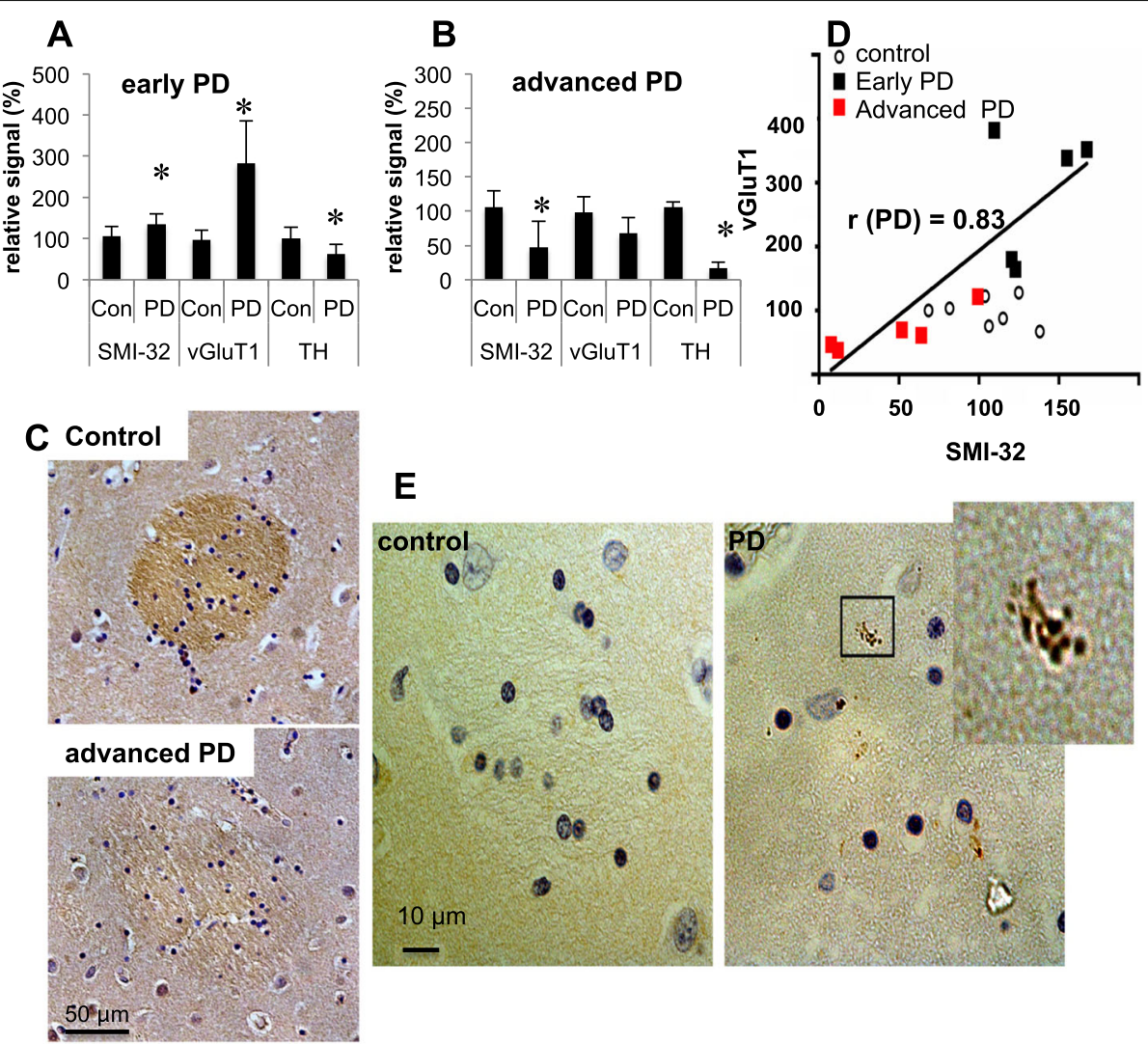

E
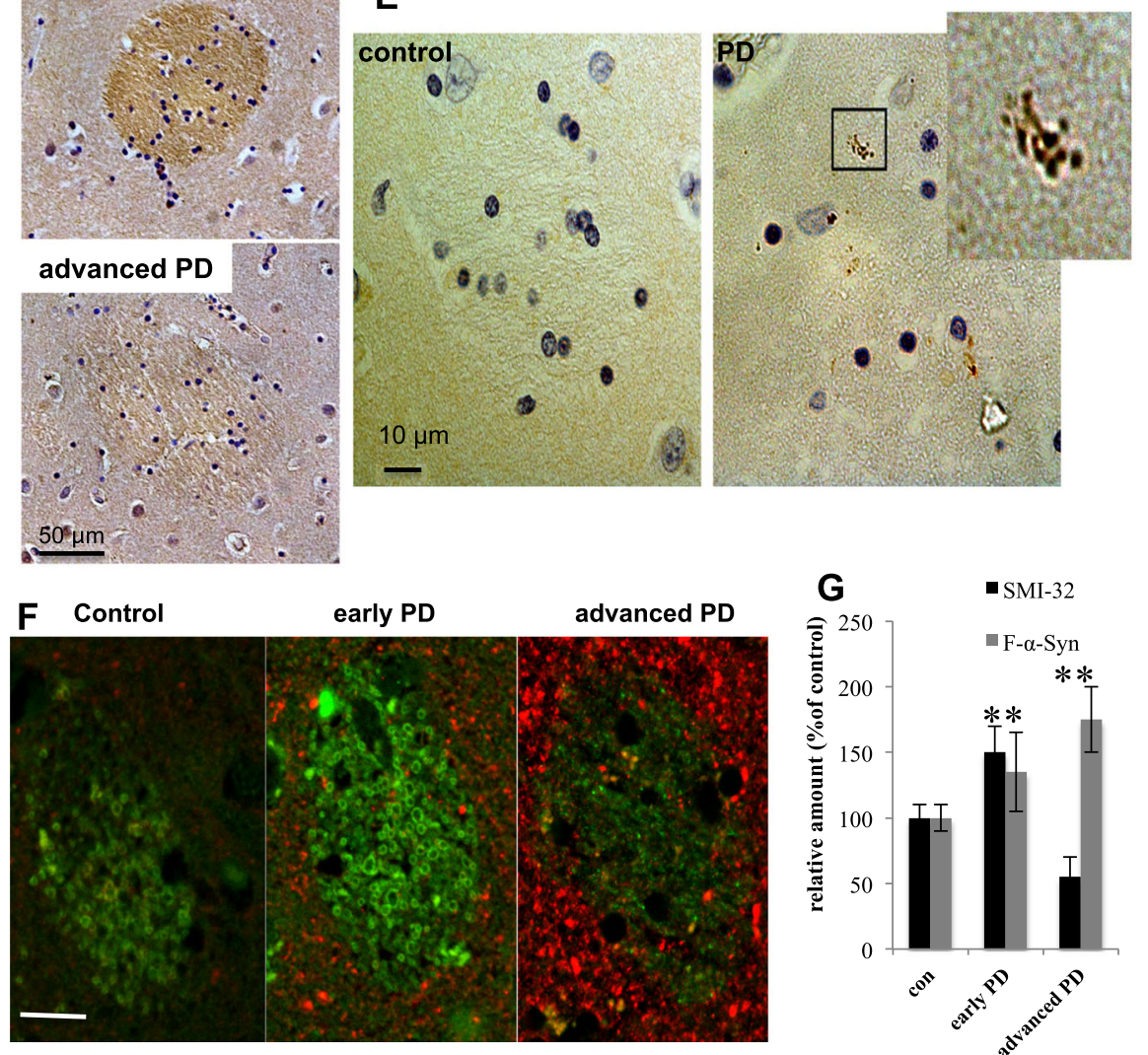

Fig. 6 Axonal plasticity in corticostriatal connections at early stages of PD a. SMI-32, vGluT1 and TH immunoreactive signals localized to the caudate of early PD (unified stage Ila and Ilb; and control brains. $N=5$ each). b A graph (as in a) showing advanced PD (Braak stages 5-6; $n=5$ ) and control brains $(n=7)$. Mean \pm SD of $5-7$ fields. ${ }^{*}, P<0.05$, ttest. $\mathbf{c} \| \mathrm{HC}$ of caudal WMTs in a control (Male, 89 years) and an advanced PD brain (Male, 82 years, Braak stage 6), immunoreacted with anti SMI-32 antibody. $\mathbf{d}$ Positive correlation (Pearson's $r$ value $=0.83$ ) between the immunoreactive signals obtained for VGluT1 and SMI-32 for PD cases. e A caudal WMT probed for a-Syn pathology by IHC. A control brain (male, 84 years) and an advanced PD (male, 75 years, Braak stage 5) brain. $\mathbf{f ~} \mathrm{HC}$ of caudal WMTs in a control brain (male, 84 years) an early PD brain (male, 72 year, unified stage Illb) and an advanced PD brain (Male 75 years, Braak stage 5). Brain sections co-immunoreacted with anti filament-aSyn and SMI-32 antibodies. Bar $=20 \mu \mathrm{m}$. g Filament-a-Syn and SMI-32 signals as in (f). Mean \pm SD of $n=10-15$ WMTs

blotting. Brain tissue punches containing the dorsal striatum of 12-14 months old mouse brains were homogenized to yield a total homogenate immediately after dissection. Protein samples of striatal homogenates $(30 \mu \mathrm{g}$ protein) were analyzed and normalized to $\beta$-actin levels detected on the same blot (Fig. 7d, e). The Western blot results confirm the finding above, indicating no differences between the tested mouse genotypes for $\mathrm{TH}$ and DAT levels in the striatum. However, synaptophysin levels were significantly higher in striatal homogenates of A53T $\alpha$-Syn (137\%) than in control brains (set at $100 \%)$. Mean of $n=5$ brains in each genotype, $P<0.05$, ttest. Supporting increases in axons and synaptic terminals. 

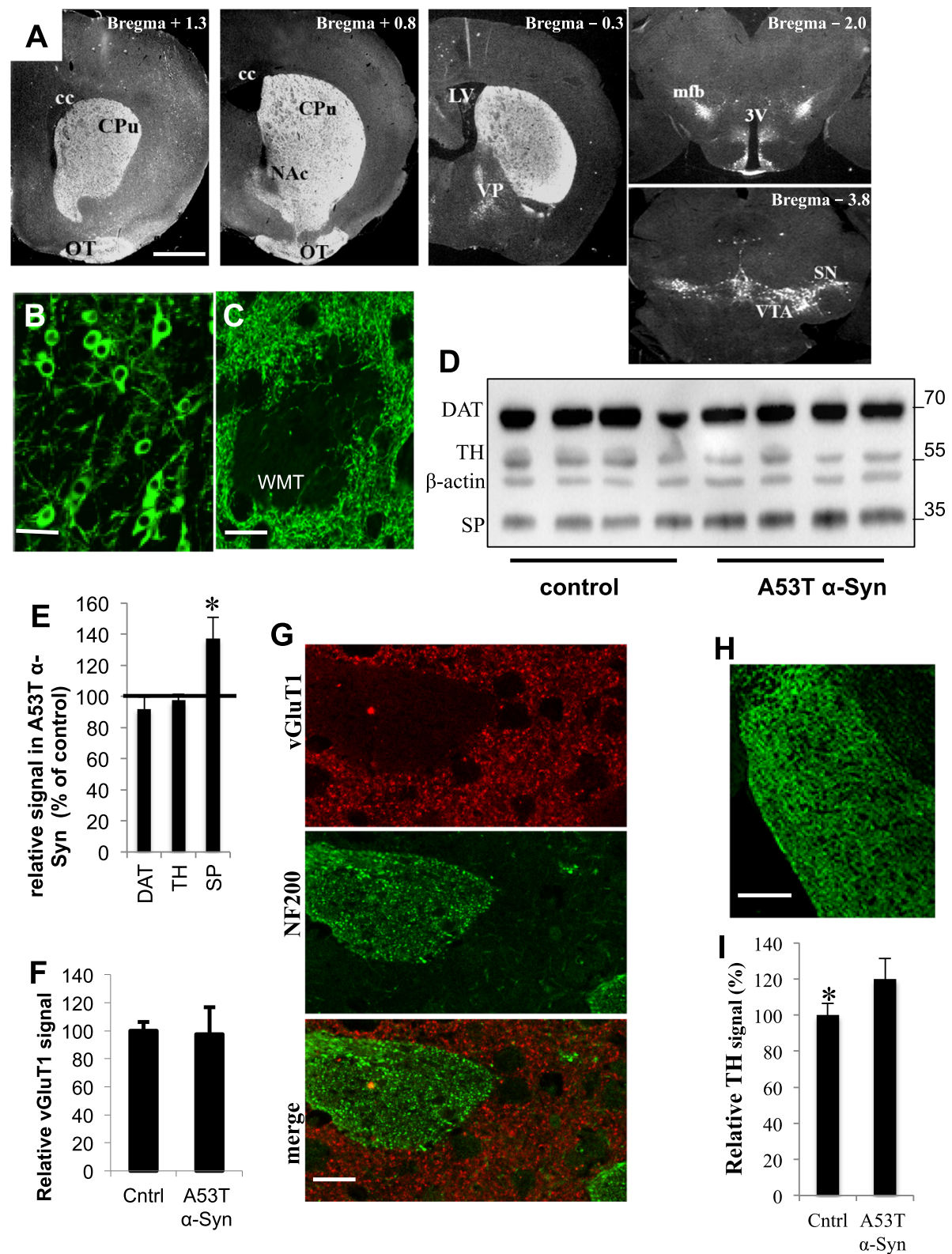

Fig. 7 The dopaminergic system in A53T a-Syn tg mouse brains. a Coronal brain sections (6 4 m, bregma $+1.3-(-3.8)$ ) of A53T a-Syn tg mouse (14 months), immunoreacted with anti Tyrosine hydroxylase (TH) antibody. CC, corpus callosum; CPu, caudate putamen; LV, lateral ventricle; mfb, medial forebrain bundle; NAc, nucleus accumbens; OT, olfactory tubercle; VP, ventral pallidum; VTA, ventral tegmental area. $3 \mathrm{~V}$, third ventricle. Bar $=500 \mu \mathrm{m}$. B-C. Higher magnification of brain sections (as in a). b SNc, Bar $=25 \mu \mathrm{m}$. c Striatal WMT. Bar $=20 \mu \mathrm{m}$. d Protein samples (30 $\mu \mathrm{g}$ ) of striatal homogenates from 12 to 14 month old A53T a-Syn tg and age matched a-Syn -/- control mouse brains analyzed by Western blotting. Blot immunoreacted with antibodies for dopamine transporter (DAT); Tyrosine hydroxylase (TH); $\beta$-actin; and synaptophysin (SP). A representative blot out of two. $N=5$ brains in each genotype. e A graph showing quantitation of blots in (d), values normalized to $\beta$-actin levels in the same sample. Vertical bar represents control brains, set at 100\%. $\mathbf{f}$ Quantitative values of Western blot as in (d) reacted with anti vGluT1 ab. $\mathbf{g}$ Immunohistochemistry (IHC) of paraffin embedded mouse brain section co-immunoreaced with anti vGlut1 (red) and anti NF-200 (green) abs. Bar $=25 \mu \mathrm{m}$. $\mathbf{h} I \mathrm{HC}$ of a paraffin embedded section containing the olfactory tubercle from an A53T a-Syn tg mouse brain at 12 month of age, coimmunoreaced with anti TH ab. i Quantification of immunoreactivity obtained by $\mathrm{HC}$ in the olfactory tubercle. Paraffin-embedded brain sections of A53T a-Syn tg and control 12-14 months old mice, immunoreacted with anti TH antibody as in (h). Mean \pm SD of $n=4$ mouse brain. ${ }^{*}, P<$ 0.05 , ttest. Bar $=100 \mu \mathrm{m}$

vGluT1 signal was quantified in the dorsal striatum, in paraffin-embedded, coronal brain sections of 12-14 months old A53T $\alpha$-Syn tg and control mouse brains, by
IHC. In addition, vGluT1 signal was assessed in tissue punches containing the dorsal striatum by Western blotting. The results show no differences in vGluT1 levels 
between mouse genotypes $(n=5-7$ mouse brains in each genotype).

Interestingly, $\mathrm{TH}$ immunoreactive signal in the olfactory tubercle, which is innervated by dopaminergic neurons residing in the ventral tegmental area (VTA) and is part of the ventral striatum, was significantly $121 \pm 15 \%$ higher in the aged A53T $\alpha$-Syn than in control mouse brains, set at $100 \%$ (Fig. 7h, i). Mean \pm SD of $n=4$ brains in each genotype, $P<0.05$, ttest.

Together, the results in the mouse brains do not show evidence for actual loss of dopaminergic axons or alterations associated with glutamatergic terminals. At the age 12-14 month, the transgenic mouse colony, which expresses the human mutant A53T $\alpha$-Syn and backcrossed to the C57BL/6JOlaHsd $\alpha$-Syn -/- mouse genotype, recapitulates characteristic features of the human disease, including accumulation of $\alpha$-Syn pathology and evidence for axonal injury, side by side with evidence for axonal growth, however, with no apparent loss of dopaminergic axons.

\section{Discussion}

We demonstrate a role for $\alpha$-Syn in mechanisms of axonal growth and plasticity, and relate the finding to pathogenic mechanisms in PD. Our results show that $\alpha$ Syn elongates the main axons and collaterals in primary neurons, with a stronger effect for the PD- associated A53T $\alpha$-Syn mutant over WT $\alpha$-Syn. The involvement of $\alpha$-Syn in axon outgrowth is mediated through its associations with membrane $\mathrm{PI} 4,5 \mathrm{P}_{2}$ phosphoinositide. In brains of mice transgenic for $\alpha$-Syn, we detect a higher density of axons, within striatal WMTs of old and symptomatic mice. The finding, obtained in two different $\alpha$ Syn tg mouse lines, suggests an involvement of $\alpha$-Syn in mechanisms of plasticity. In accord, in human PD brains we detect evidence for a higher axon density within corticostriatal, glutamatergic, WMTs at early stages of the disease. The increases in corticostriatal plasticity fit with previous indications for the occurrence of compensatory glutamatergic mechanisms in PD. These compensatory mechanisms are suggested to follow dopaminergic denervation, which underlies presentation of characteristic disease symptoms. However, side by side with enhanced plasticity at early PD, we also detected accumulation of $\alpha$-Syn toxicity. With disease progression and further loss of dopamine, the corticostriatal glutamatergic WMTs degenerate (see Fig. 8 for illustrative summary).

Early studies have shown that $\alpha$-Syn preferentially binds acidic phospholipids [44]. In this study, we found that $\alpha$ Syn regulates PM levels of the acidic phosphoinositide, $\mathrm{PI} 4,5 \mathrm{P}_{2}$. We suggest that the mechanism through which $\alpha$-Syn regulates PI4, $5 \mathrm{P}_{2}$ levels involves Nir2 activity. Nir2 supports the maintenance of PI4,5 $\mathrm{P}_{2}$ pool on the PM. It acts at endoplasmic reticulum (ER)-PM contact sites [28,

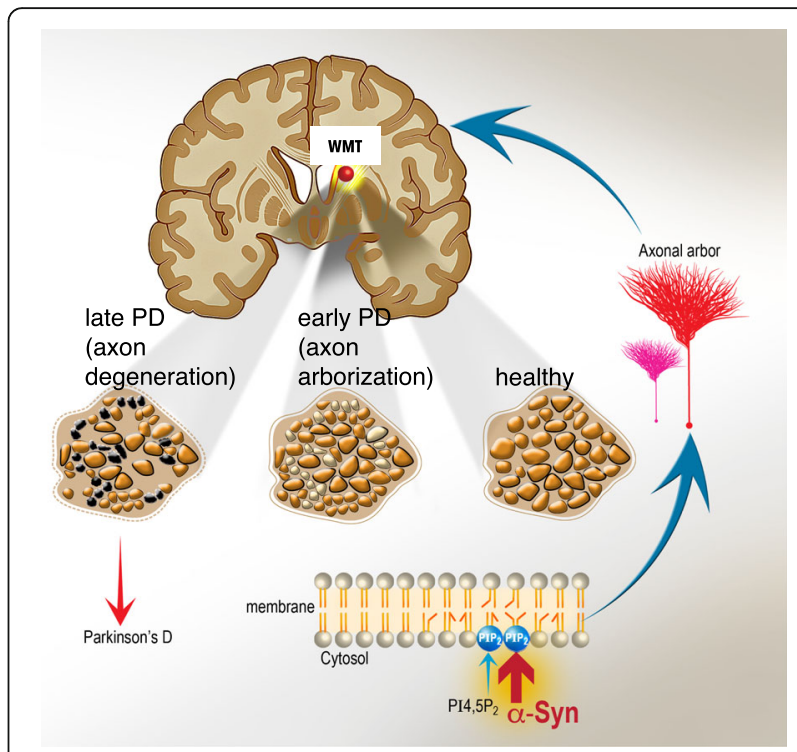

Fig. 8 Illustrative synopsis. a-Syn enriches axon membrane with the acidic phosphoinositide $\mathrm{PI} 4,5 \mathrm{P}_{2}$ to facilitate axon outgrowth and arborization. In brains affected with PD, over expression or

mutations in a-Syn increase axon density at early stages of the disease and enhance glutamatergic plasticity in caudal white matter tracts (WMTs). However, with disease progression, accumulation of damage is leading to degeneration and loss of axons within WMTs

50] to transfer a newly synthesized phosphatidyl inositol (PI) from the ER to the PM in exchange for phosphatidic acid (PA), in a mechanism that is tightly coupled with the hydrolysis of $\mathrm{PI} 4,5 \mathrm{P}_{2}$ by phospholipase $\mathrm{C}$ (PLC). The higher levels of PI4,5P 2 on PM of $\alpha$-Syn expressing axons may facilitate outgrowth and arborization through phosphorylated GAP-43 [51-53]. GAP-43 phosphorylation at Ser41 was shown to regulate actin filament length by increasing stabilization/polymerization of F-actin in a PI4, $5 \mathrm{P}_{2}$-dependent mechanism [54].

The results link increases in axonal $\mathrm{PI} 4,5 \mathrm{P}_{2}$ levels with $\alpha$-Syn toxicity in PD. One obvious limitation of studying phosphoinositides in human brains is their reported instability accounted for the differences in post mortem intervals [55]. Because of this concern we have not assessed PI4,5P $\mathrm{P}_{2}$ levels in the post mortem human brains. Based on our findings in brains of mice modeling $\mathrm{PD}$, we suggest a model for $\alpha$-Syn toxicity in PD that involves increases in $\mathrm{PI} 4,5 \mathrm{P}_{2}$, which leads to elongation of axons and collaterals, and in parallel, enhances the accumulation of axonal damage. The mouse model successfully recapitulates the increases in glutamatergic, SMI-32 positive, axon density that is detected in the PD brains. However, a drawback of this study is the lack of evidence for alteration in $\mathrm{PI} 4,5 \mathrm{P}_{2}$ in the human brains.

With regards to the experiments performed with human brains, the early and advanced PD cases were obtained from two different sources. A plausible concern is 
that the disease stage-dependent differences we detect may result from differences in protocols of post mortem tissue processing and/or post mortem intervals. It is important to emphasize that control cases in this study were obtained from both resources.

Parkinson's disease is caused due to the loss of dopamine producing nerve cells [56]. The predominantly vulnerable dopaminergic neurons in $\mathrm{PD}$ are the dopaminergic neurons that reside in the SNc and innervate the dorsal striatum. Whereas the dopaminergic neurons in the VTA, which innervate the ventral striatum, are less affected [56-60] and were shown to resist $\alpha$-Syn toxicity [61]. A characteristic feature of the dopaminergic neurons of the $\mathrm{SNc}$ is a complex axonal arbor with an exceptionally high number of synapses in the striatum. This feature enables broad connectivity and neuroplasticity [62], and on the other hand, may underlie their specific vulnerability in PD, attributed to a high energetic burden [63]. The findings herein, support a role for $\alpha$-Syn in axon outgrowth and arborization.

The A53T $\alpha$-Syn tg mouse model [20] was backcrossed to the C57BL/6JOlaHsd $\alpha$-Syn -/- genotype to silence endogenous $\alpha$-Syn. In its original description [20], the THpositive neurons of this mouse model appeared unaffected and in our analysis, no overt loss in TH immunoreactivity could be detected (Fig. 7). Absence of evidence for actual loss of dopaminergic neurons was reported also for an $\alpha$ Syn tg rat model [64]. We suggest that the lack of evidence for TH-positive axon loss in the dorsal striatum of A53T $\alpha$-Syn tg mouse brains may represent a steady state between two opposing mechanisms taking place simultaneously in the aged transgenic mouse brain, namely, axon growth and axon degeneration.

Of relevance, compensatory mechanisms have been suggested to take place at early stages of PD. Surviving dopaminergic neurons appear to go through functional changes aimed at preserving dopamine availability [65]. Experiments in animal models performed following acute chemical-induced lesion in the SNc [12], demonstrated compensatory axonal branching in association with improvement in animals' motor performances. Additional, non-dopaminergic mechanisms, are activated to support the changes in dopamine homeostasis $[65,66]$. The loss of dopamine appears to disrupt a functional interplay between dopamine and glutamate in brains affected with PD [67-70]. It has been reported that glutamatergic transmission to the striatum is increased in PD [71]. This plasticity of the glutamatergic system in response to the loss of dopamine includes increases in synaptic strength and corticostriatal glutamatergic transmission at the remaining synapses [72, 73]. Glutamatergic terminals in striatum may represent either thalamic or corticostriatal axons. Utilizing vGluT1, a marker for corticostriatal terminals and vGlut2, a marker for thalamostriatal terminals [74-77], it was previously reported that the corticostriatal terminals are increased in the putamen of PD brains [71]. Increases in vGluT1 terminals were also detected in the striatum of chronically MPTP-treated parkinsonian monkeys [78]. In line with these reports, our findings show higher striatal vGluT1 levels at early stages of PD. We now suggest that the mechanism through which glutamatergic synapses respond to the denervation of dopaminergic axons involves plasticity of corticostriatal connections, attributed to $\alpha$ Syn' effects to enhance axon outgrowth.

Two missense mutations in the sac domain of the PI4, $5 \mathrm{P}_{2}-5$-phosphatase $\mathrm{Sj}-1, \mathrm{R} 258 \mathrm{Q}$ and $\mathrm{R} 459 \mathrm{P}$, were recently discovered in patients affected with autosomal recessive form of early-onset Parkinsonism [79-81]. Importantly, a knock-in mouse carrying the R258Q mutation showed axonal degeneration that was selectively observed in dopaminergic axons in the dorsal striatum [82]. These recent reports support a role for phosphoinositides (PIP)s in mechanisms of PD. Of relevance, $\alpha$-Syn over expression was shown to associate with impaired cytoskeleton [83, 84]; neurite outgrowth and integrity [85]; and membrane trafficking [86]. A common denominator shared by these mechanisms is the involvement of PIPs. It is plausible that differences in metabolism of PIPs, between model systems, may explain the high variability in reported effects of $\alpha$-Syn in neurite outgrowth and integrity [85, 87], or in membrane trafficking [86].

Our understanding of the sequence of pathogenic events leading to PD is incomplete. It is agreed that loss of nigrostriatal dopaminergic inputs to the dorsal striatum is the central cause for the cardinal motor features of PD. However, the pathophysiology of PD extends beyond the $\mathrm{SNc}$, where the dopaminergic neurons reside. An ordered and predicted disease propagation path, which affects the peripheral nervous system and propagates to the central nervous system, fits well with Braak hypothesis $[2,56,88$, 89]. This hypothesis suggests that Lewy pathology in the central nervous system (CNS) propagates in a caudal to -rostral direction, starting at the lower brainstem and the olfactory system at early stages and spreading out to the neocortex at late stages of the disease $[2,56,89,90]$. However, side by side with the growing support, it is important to also consider evidences that do not directly line up with Braak hypothesis [3]. A recently described viewpoint suggests a different and complementary sequence of events for PD pathogenesis. According to which, the neocortex is not necessarily a final stage of a bottom-up sequence, rather, it is involved early in disease, initiating a top-down sequence that may disturb the vulnerable dopaminergic neurons. Involvement of the neocortex in disease mechanisms may explain the paradox of focal onset of motor signs in PD [91]. However, a top-down progression is not supported by autopsy series with large numbers of PD and normal aging subjects [3]. With relevance to this debate, 
we show degeneration of corticostriatal, SMI-32 positive WMTs, at advanced stages of the disease, along with accumulation of characteristic PD pathology. However, our results also show alterations in corticostriatal, SMI-32 immunoreactive WMTs, early in PD when loss of caudal $\mathrm{TH}$ is apparent. This involvement of the cortical glutamatergic connections at early stages of the disease may be critical for understanding the potential involvement of the neocortex in focal onset of motor signs in PD.

\section{Conclusions}

$\alpha$-Syn is involved in the regulation of plasma membrane

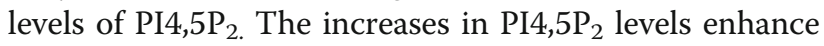
axon arbor. However, excessive growth of the axons is associated with accumulation of damage and is implicated in mechanisms of Parkinson's disease (Fig. 8).

\section{Supplementary information}

Supplementary information accompanies this paper at https://doi.org/10. 1186/s13024-020-00370-y.

Additional file 1. Table S1. Post mortem human brains. Table S2. list of antibodies.

Additional file 2 Supplementary Fig. S1. a-Syn expression enhances axonal growth in primary hippocampal, mesencephalic and cortical neurons. A. Primary hippocampal cultures from a-Syn ${ }^{-1-}$ (C57BL/6JOlaHsd) mouse brains, virally transduced either with WT a-Syn, A53T a-Syn, K10,12E a-Syn, or a mock-GFP vector. Cells were fixed at 4 DIV and immunoreacted with antibodies against a-Syn (MJFR1, green), a-tubulin (white) and PI4,5P (red). Direct fluorescence was captured for GFP (green). Bar = $25 \mu \mathrm{m}$. B. Graph showing the average length of the main extension designated as axons (in $\mu \mathrm{m}$ ); C. Total length of collaterals per axon (in $\mu \mathrm{m}$ ); and D. PI4,5P 2 levels within the main axon and its collaterals (per $\mu \mathrm{m}^{2}$ area) quantified by Fiji (Image J) program. Mean $\pm \mathrm{SE} ; n>17$ cells; ${ }^{*}, P<$ 0.05; Bar $=5 \mu \mathrm{m}$. E. Cortical neurons cultured and treated as in Fig. 2, expressing A30P a-Syn mutation, WT a-Syn or GFP (mock). Mean \pm SE; $n>$ 15 cells; ${ }^{*}, P<0.05$. F-G. Primary mesencephalic neurons at 4 DIV from $a-$ $\mathrm{Syn}^{-1-}$ mouse brains. Neurons were virally transduced to co-express aSyn and a mock plasmid, a-Syn and PIPKIy or a-Syn and Sj-1. Control neurons expressed a mock GFP plasmid, Cultured neurons immunoreacted (as in A) with anti TH antibody to verify dopaminergic properties, indicated $\sim 90 \%$ positivity. F. Average length of the main extension designated as axons (in $\mu \mathrm{m}$ ); $\mathrm{G}$. Total length of collaterals per axon (in $\mu \mathrm{m}$ ); and $\mathrm{H}$. PI4,5P 2 levels within the main axon and its collaterals (per $\mu \mathrm{m}^{2}$ area) quantified by Fiji (Image J) program. Mean \pm SE; $n>20$ cells; ${ }^{*}, P<$ 0.05. Supplementary Fig. S2. Specificity of PI4,5P 2 signal. A. Specificity of $\mathrm{PI} 4,5 \mathrm{P}_{2}$ signal is detected by ICC in primary neurons, following activation of muscarinic receptors with carbachol (Sigma Aldrich) and PLC-mediated hydrolysis of $\mathrm{PI} 4,5 \mathrm{P}_{2}$. Primary cortical neurons at $5 \mathrm{DIV}$, treated with $1 \mathrm{mM}$ carbachol for 12 minutes. Bar $=20 \mu \mathrm{M}$. B. Higher magnification of a cortical neuron (as in $\mathrm{A}$ ), demonstrating $\mathrm{PI} 4,5 \mathrm{P}_{2}$ signal on PM surrounding cell body. HEK 293 T cells transiently expressing the rapamycin-induced translocatable CFP-PIPK kinase. CFP-PIPK fluorescence is either cytosolic or on the PM in DMSO or rapamycin (respectively) treated cells. CFP-PIPK (blue) is directly detected at $485 \mathrm{~nm}$ and PI4,5P 2 detected by ICC with anti $\mathrm{PI} 4,5 \mathrm{P}_{2}$ ab (red). Bar $=10 \mu \mathrm{M}$. Supplementary Fig. S3. vGluT1 and TH immunoreactivity in control and PD brains. Slides containing caudate of a control (Male 85 years, $3 \mathrm{~h}$ PMI) and an early PD case (male 83 years, $2 \mathrm{~h}$ PMI, Unified stage Ila), immunoreacted with anti vGluT1 (red) and anti TH (green) antibodies. Bar $=10 \mu \mathrm{m}$.

\section{Abbreviations}

a-Syn: a-Synuclein (a-Syn); APP: Amyloid precursor protein; CNS: Central nervous system; DAG: Diacylglycerol; DAT: Dopamine transporter;
ICC: Immunocytochemistry; IHC: Immunohistochemistry; NF: Neurofilament; PD: Parkinson's disease; PI: Phosphatidyl inositol; PI4,5P2: Phosphatidylinositol 4,5-bisphosphate; PIP: Phosphoinositides; PIPKI: PIP-5 kinase; PLC: Phospholipase C; PM: Plasma membrane; Sj-1: Synaptojanin-1; SNc: Substantia nigra pars compacta; $\mathrm{TH}$ : Thyrosine hydroxylase; vGluT1: Vesicular glutamate transporter 1; VTA: Ventral tegmental area; WMT: White matter tract

\section{Acknowledgments}

The authors would like to thank Drs. Glenda Halliday and Jeffrey $\mathrm{H}$. Kordower, and Prof. Dr. Christiane Richter Landsberg for their critical advice; Dr. David Arkadir for helpful comments during manuscript preparation; and Mr. Aviv D. Mizrahi-Kliger for a critical reading of the manuscript.

The authors thank the Multiple Sclerosis Society of Great Britain and Northern Ireland and the Banner Sun Health Research Institute, Sun City, Arizona, USA for their support of this study.

We are grateful to the Banner Sun Health Research Institute Brain and Body Donation Program of Sun City, Arizona for the provision of human brain sections.

\section{Authors' contributions}

MS., designed, performed the analyses and collected the data. JG., HG, and SAEH., performed analyses, collected and analyzed data. TGB, and GES, selected appropriate human tissue and clinicopathological data. M.S., and R.S., wrote the manuscript. RS, conceived the study. All authors read and approved the final manuscript.

\section{Funding}

The Brain and Body Donation Program has been supported by the National Institute of Neurological Disorders and Stroke (U24 NS072026 National Brain and Tissue Resource for Parkinson's Disease and Related Disorders), the National Institute on Aging (P30 AG19610 Arizona Alzheimer's Disease Core Center), the Arizona Department of Health Services (contract 211002, Arizona Alzheimer's 1001 to the Arizona Parkinson's Disease Consortium) and the Michael J. Fox Foundation for Parkinson's Research.

This study was funded by Israel Science Foundation grant \#182/12.

\section{Availability of data and materials}

All data generated or analyzed during this study are included in this published article [and its supplementary information files].

\section{Ethics approval and consent to participate}

The approval for the use of human tissue material was obtained from The Peer Review Panel of the Parkinson's UK Brain Bank and the Brain and Body Donation Program at Sun Health Research Institute; the latter's operations are approved by the Western Institutional Review Board (Seattle, WA). This study was carried out in strict accordance with the recommendations in the Guide for the Care and Use of Laboratory Animals of the National Institutes of Health. Adequate measures were taken to minimize pain and suffering. All animal welfare and experimental protocols were approved by the Committee for the Ethics of Animal Experiments of the Hebrew University of Jerusalem NIH approval \# OPRR-A01-5011 (Permit number: MD16-14,826-3).

\section{Consent for publication}

Not applicable

\section{Competing interests}

The authors declare that they have no competing interest.

\section{Author details}

${ }^{1}$ Department of Biochemistry and Molecular Biology, IMRIC, The Hebrew University-Hadassah Medical School, Ein Kerem, 9112001 Jerusalem, Israel. 2Electron Microscopy Unit, The Hebrew University-Hadassah Medical School, Ein Kerem, 9112001 Jerusalem, Israel. ${ }^{3}$ McGovern Institute for Brain Research and Department of Brain and Cognitive Sciences, Massachusetts Institute of Technology, Cambridge, MA 02139, USA. ${ }^{4}$ Banner Sun Health Research Institute, Sun City, AZ, USA. 
Received: 16 December 2019 Accepted: 25 February 2020 Published online: 30 March 2020

\section{References}

1. Goedert M, Spillantini MG, Del Tredici K, Braak H. 100 years of Lewy pathology. Nat Rev Neurol. 2013;9(1):13-24.

2. Braak H, Del Tredici K, Rub U, de Vos RA, Jansen Steur EN, Braak E. Staging of brain pathology related to sporadic Parkinson's disease. Neurobiol Aging. 2003;24(2):197-211.

3. Beach TG, Adler CH, Lue L, Sue LI, Bachalakuri J, Henry-Watson J, et al. Unified staging system for Lewy body disorders: correlation with nigrostriatal degeneration, cognitive impairment and motor dysfunction. Acta Neuropathol. 2009;117(6):613-34.

4. Braak H, Del Tredici K. Neuroanatomy and pathology of sporadic Parkinson's disease. Adv Anat Embryol Cell Biol. 2009;201:1-119.

5. Orimo S, Uchihara T, Kanazawa T, Itoh Y, Wakabayashi K, Kakita A, et al. Unmyelinated axons are more vulnerable to degeneration than myelinated axons of the cardiac nerve in Parkinson's disease. Neuropathol Appl Neurobiol. 2011;37(7):791-802.

6. Braak H, Bohl JR, Muller CM, Rub U, de Vos RA, Del Tredici K. Stanley Fahn lecture 2005: the staging procedure for the inclusion body pathology associated with sporadic Parkinson's disease reconsidered. Mov Disord. 2006;21(12):2042-51

7. George JM. The synucleins. Genome Biol. 2002;3(1):1-6.

8. Gruschus JM. Did alpha-Synuclein and Glucocerebrosidase coevolve? Implications for Parkinson's Disease. PLoS One. 2015;10(7):e0133863.

9. Clayton DF, George JM. The synucleins: a family of proteins involved in synaptic function, plasticity, neurodegeneration and disease. Trends Neurosci. 1998;21(6):249-54.

10. Zullo $L$, Hochner $B$. A new perspective on the organization of an invertebrate brain. Commun Integr Biol. 2011;4(1):26-9.

11. Haber SN. Corticostriatal circuitry. Dialogues Clin Neurosci. 2016;18(1):7-21.

12. Arkadir D, Bergman H, Fahn S. Redundant dopaminergic activity may enable compensatory axonal sprouting in Parkinson disease. Neurology. 2014:82(12):1093-8.

13. Choi S, Thapa N, Tan X, Hedman AC, Anderson RA. PIP kinases define $\mathrm{PI} 4,5 \mathrm{P}(2)$ signaling specificity by association with effectors. Biochim Biophys Acta. 2015;1851(6):711-23.

14. Yamazaki M, Yamauchi Y, Goshima Y, Kanaho Y. Phosphatidylinositol 4phosphate 5-kinase beta regulates growth cone morphology and semaphorin 3A-triggered growth cone collapse in mouse dorsal root ganglion neurons. Neurosci Lett. 2013;547:59-64.

15. Noda Y, Niwa S, Homma N, Fukuda H, Imajo-Ohmi S, Hirokawa N. Phosphatidylinositol 4-phosphate 5-kinase alpha (PIPKalpha) regulates neuronal microtubule depolymerase kinesin, KIF2A and suppresses elongation of axon branches. Proc Natl Acad Sci U S A. 2012;109(5):1725-30.

16. Hernandez-Deviez DJ, Roth MG, Casanova JE, Wilson JM. ARNO and ARF6 regulate axonal elongation and branching through downstream activation of phosphatidylinositol 4-phosphate 5-kinase alpha. Mol Biol Cell. 2004;15(1): 111-20.

17. van Horck FP, Lavazais E, Eickholt BJ, Moolenaar WH, Divecha N. Essential role of type I (alpha) phosphatidylinositol 4-phosphate 5-kinase in neurite remodeling. Curr Biol. 2002;12(3):241-5.

18. Toyofuku T, Yoshida J, Sugimoto T, Zhang H, Kumanogoh A, Hori M, et al. FARP2 triggers signals for Sema3A-mediated axonal repulsion. Nat Neurosci. 2005:8(12):1712-9.

19. Weinkove D, Bastiani M, Chessa TA, Joshi D, Hauth L, Cooke FT, et al. Overexpression of PPK-1, the Caenorhabditis elegans type I PIP kinase, inhibits growth cone collapse in the developing nervous system and causes axonal degeneration in adults. Dev Biol. 2008:313(1):384-97.

20. Giasson BI, Duda JE, Quinn SM, Zhang B, Trojanowski JQ, Lee VM. Neuronal alpha-synucleinopathy with severe movement disorder in mice expressing A53T human alpha-synuclein. Neuron. 2002;34(4):521-33.

21. Specht CG, Schoepfer R. Deletion of the alpha-synuclein locus in a subpopulation of C57BL/6J inbred mice. BMC Neurosci. 2001;2(1):11

22. Yakunin E, Loeb V, Kisos H, Biala Y, Yehuda S, Yaari Y, et al. Alpha-synuclein neuropathology is controlled by nuclear hormone receptors and enhanced by docosahexaenoic acid in a mouse model for Parkinson's disease. Brain Pathol. 2012;22(3):280-94.

23. Grigoletto J, Pukass K, Gamliel A, Davidi D, Katz-Brull R, Richter-Landsberg C, et al. Higher levels of myelin phospholipids in brains of neuronal alpha-
Synuclein transgenic mice precede myelin loss. Acta Neuropathol Commun 2017;5(1):37.

24. Rockenstein E, Mallory M, Hashimoto M, Song D, Shults CW, Lang I, et al. Differential neuropathological alterations in transgenic mice expressing alpha-synuclein from the platelet-derived growth factor and Thy-1 promoters. J Neurosci Res. 2002;68(5):568-78.

25. Rockenstein E, Nuber S, Overk CR, Ubhi K, Mante M, Patrick C, et al. Accumulation of oligomer-prone alpha-synuclein exacerbates synaptic and neuronal degeneration in vivo. Brain. 2014;137(Pt 5):1496-513.

26. Fleming SM, Salcedo J, Fernagut PO, Rockenstein E, Masliah E, Levine MS, et al. Early and progressive sensorimotor anomalies in mice overexpressing wild-type human alpha-synuclein. J Neurosci. 2004;24(42):9434-40.

27. Oakley H, Cole SL, Logan S, Maus E, Shao P, Craft J, et al. Intraneuronal betaamyloid aggregates, neurodegeneration, and neuron loss in transgenic mice with five familial Alzheimer's disease mutations: potential factors in amyloid plaque formation. J Neurosci. 2006;26(40):10129-40.

28. Kim S, Kedan A, Marom M, Gavert N, Keinan O, Selitrennik M, et al. The phosphatidylinositol-transfer protein Nir2 binds phosphatidic acid and positively regulates phosphoinositide signalling. EMBO Rep. 2013;14(10):891-9.

29. Stauffer TP, Ahn S, Meyer T. Receptor-induced transient reduction in plasma membrane Ptdlns(4,5)P2 concentration monitored in living cells. Curr Biol. 1998;8(6):343-6.

30. Perera RM, Zoncu R, Lucast L, De Camilli P, Toomre D. Two synaptojanin 1 isoforms are recruited to clathrin-coated pits at different stages. Proc Natl Acad Sci U S A. 2006;103(51):19332-7.

31. Di Paolo G, Pellegrini L, Letinic K, Cestra G, Zoncu R, Voronov S, et al. Recruitment and regulation of phosphatidylinositol phosphate kinase type 1 gamma by the FERM domain of Talin. Nature. 2002;420(6911):85-9.

32. Dittgen T, Nimmerjahn A, Komai S, Licznerski P, Waters J, Margrie TW, et al. Lentivirus-based genetic manipulations of cortical neurons and their optical and electrophysiological monitoring in vivo. Proc Natl Acad Sci U S A. 2004; 101(52):18206-11.

33. Suh BC, Inoue T, Meyer T, Hille B. Rapid chemically induced changes of Ptdlns(4,5)P2 gate KCNQ ion channels. Science. 2006:314(5804):1454-7.

34. Friedman HV, Bresler T, Garner CC, Ziv NE. Assembly of new individual excitatory synapses: time course and temporal order of synaptic molecule recruitment. Neuron. 2000;27(1):57-69.

35. Zaltieri M, Grigoletto J, Longhena F, Navarria L, Favero G, Castrezzati S, et al. Alpha-synuclein and synapsin III cooperatively regulate synaptic function in dopamine neurons. J Cell Sci. 2015;128(13):2231-43.

36. Vieira MM, Schmidt J, Ferreira JS, She K, Oku S, Mele M, et al. Multiple domains in the C-terminus of NMDA receptor GluN2B subunit contribute to neuronal death following in vitro ischemia. Neurobiol Dis. 2016:89:223-34.

37. Phan TK, Lay FT, Poon IK, Hinds MG, Kvansakul M, Hulett MD. Human betadefensin 3 contains an oncolytic motif that binds PI(4,5)P2 to mediate tumour cell permeabilisation. Oncotarget. 2016;7(2):2054-69.

38. Cockcroft S, Bennett JP, Gomperts BD. The dependence on Ca2+ of phosphatidylinositol breakdown and enzyme secretion in rabbit neutrophils stimulated by formylmethionyl-leucylphenylalanine or ionomycin. Biochem J. 1981;200(3):501-8

39. Loeb V, Yakunin E, Saada A, Sharon R. The transgenic overexpression of alpha-synuclein and not its related pathology associates with complex I inhibition. J Biol Chem. 2010:285(10):7334-43.

40. Howell OW, Schulz-Trieglaff EK, Carassiti D, Gentleman SM, Nicholas R, Roncaroli $F$, et al. Extensive grey matter pathology in the cerebellum in multiple sclerosis is linked to inflammation in the subarachnoid space. Neuropathol Appl Neurobiol. 2015;41(6):798-813.

41. Haas AJ, Prigent S, Dutertre S, Le Drean Y, Le Page Y. Neurite analyzer: an original Fiji plugin for quantification of neuritogenesis in two-dimensional images. J Neurosci Methods. 2016:271:86-91.

42. Sturrock RR. Myelination of the mouse corpus callosum. Neuropathol Appl Neurobiol. 1980;6(6):415-20.

43. Zarbiv Y, Simhi-Haham D, Israeli E, Elhadi SA, Grigoletto J, Sharon R. Lysine residues at the first and second KTKEGV repeats mediate alpha-Synuclein binding to membrane phospholipids. Neurobiol Dis. 2014;70:90-8.

44. Davidson WS, Jonas A, Clayton DF, George JM. Stabilization of alphasynuclein secondary structure upon binding to synthetic membranes. J Biol Chem. 1998;273(16):9443-9.

45. Hamilton SE, Nathanson NM. The M1 receptor is required for muscarinic activation of mitogen-activated protein (MAP) kinase in murine cerebral cortical neurons. J Biol Chem. 2001;276(19):15850-3. 
46. Davidi D, Schechter M, Abd Elhadi S, Matatov A, Nathanson L, Sharon R. aSynuclein translocates to the nucleus to activate retinoic acid- dependent gene transcription. IScience. 2019:23(3):100910.

47. Voelker CC, Garin N, Taylor JS, Gahwiler BH, Hornung JP, Molnar Z. Selective neurofilament (SMI-32, FNP-7 and N200) expression in subpopulations of layer $\checkmark$ pyramidal neurons in vivo and in vitro. Cereb Cortex. 2004;14(11):1276-86.

48. Gentleman SM, Nash MJ, Sweeting CJ, Graham DI, Roberts GW. Betaamyloid precursor protein (beta APP) as a marker for axonal injury after head injury. Neurosci Lett. 1993;160(2):139-44.

49. Lassen LB, Gregersen E, Isager AK, Betzer C, Kofoed RH, Jensen PH. ELISA method to detect alpha-synuclein oligomers in cell and animal models. PLoS One. 2018;13(4):e0196056.

50. Chang CL, Hsieh TS, Yang TT, Rothberg KG, Azizoglu DB, Volk E, et al. Feedback regulation of receptor-induced $\mathrm{Ca} 2+$ signaling mediated by $\mathrm{E}$ Syt1 and Nir2 at endoplasmic reticulum-plasma membrane junctions. Cell Rep. 2013;5(3):813-25.

51. Aarts LH, Schrama LH, Hage WJ, Bos JL, Gispen WH, Schotman P. B-50/GAP43-induced formation of filopodia depends on rho-GTPase. Mol Biol Cell. 1998;9(6):1279-92.

52. Wiederkehr A, Staple J, Caroni P. The motility-associated proteins GAP-43, MARCKS, and CAP-23 share unique targeting and surface activity-inducing properties. Exp Cell Res. 1997;236(1):103-16.

53. Meiri KF, Saffell JL, Walsh FS, Doherty P. Neurite outgrowth stimulated by neural cell adhesion molecules requires growth-associated protein-43 (GAP43) function and is associated with GAP-43 phosphorylation in growth cones. J Neurosci. 1998;18(24):10429-37.

54. Leu B, Koch E, Schmidt JT. GAP43 phosphorylation is critical for growth and branching of retinotectal arbors in zebrafish. Dev Neurobiol. 2010;70(13): 897-911.

55. Idevall-Hagren O, De Camilli P. Detection and manipulation of phosphoinositides. Biochim Biophys Acta. 2015;1851(6):736-45.

56. Braak H, Ghebremedhin E, Rub U, Bratzke H, Del Tredici K. Stages in the development of Parkinson's disease-related pathology. Cell Tissue Res. 2004; 318(1):121-34

57. Uhl GR, Hedreen JC, Price DL. Parkinson's disease: loss of neurons from the ventral tegmental area contralateral to therapeutic surgical lesions. Neurology. 1985;35(8):1215-8.

58. Hirsch E, Graybiel AM, Agid YA. Melanized dopaminergic neurons are differentially susceptible to degeneration in Parkinson's disease. Nature. 1988;334(6180):345-8.

59. Kish SJ, Shannak K, Hornykiewicz O. Uneven pattern of dopamine loss in the striatum of patients with idiopathic Parkinson's disease. Pathophysiologic and clinical implications. N Engl J Med. 1988;318(14):876-80.

60. Damier P, Hirsch EC, Agid Y, Graybiel AM. The substantia nigra of the human brain. II. Patterns of loss of dopamine-containing neurons in Parkinson's disease. Brain. 1999;122(Pt 8):1437-48.

61. Maingay M, Romero-Ramos M, Carta M, Kirik D. Ventral tegmental area dopamine neurons are resistant to human mutant alpha-synuclein overexpression. Neurobiol Dis. 2006;23(3):522-32.

62. Kalil K, Dent EW. Branch management: mechanisms of axon branching in the developing vertebrate CNS. Nat Rev Neurosci. 2014;15(1):7-18.

63. Bolam JP, Pissadaki EK. Living on the edge with too many mouths to feed: why dopamine neurons die. Mov Disord. 2012;27(12):1478-83.

64. Cannon JR, Geghman KD, Tapias V, Sew T, Dail MK, Li C, et al. Expression of human E46K-mutated alpha-synuclein in BAC-transgenic rats replicates early-stage Parkinson's disease features and enhances vulnerability to mitochondrial impairment. Exp Neurol. 2013;240:44-56.

65. Zigmond MJ, Abercrombie ED, Berger TW, Grace AA, Stricker EM. Compensations after lesions of central dopaminergic neurons: some clinical and basic implications. Trends Neurosci. 1990;13(7):290-6.

66. Bezard E, Gross CE, Brotchie JM. Presymptomatic compensation in Parkinson's disease is not dopamine-mediated. Trends Neurosci. 2003;26(4):215-21.

67. Graybiel AM. Neurotransmitters and neuromodulators in the basal ganglia. Trends Neurosci. 1990;13(7):244-54.

68. Kotter R. Postsynaptic integration of glutamatergic and dopaminergic signals in the striatum. Prog Neurobiol. 1994;44(2):163-96.

69. Starr MS. Glutamate/dopamine D1/D2 balance in the basal ganglia and its relevance to Parkinson's disease. Synapse. 1995;19(4):264-93.

70. Calabresi P, Pisani A, Centonze D, Bernardi G. Synaptic plasticity and physiological interactions between dopamine and glutamate in the striatum. Neurosci Biobehav Rev. 1997;21(4):519-23.
71. Kashani A, Betancur C, Giros B, Hirsch E, El Mestikawy S. Altered expression of vesicular glutamate transporters VGLUT1 and VGLUT2 in Parkinson disease. Neurobiol Aging. 2007;28(4):568-78.

72. Villalba RM, Mathai A, Smith Y. Morphological changes of glutamatergic synapses in animal models of Parkinson's disease. Front Neuroanat. 2015;9: 117.

73. Udupa K, Chen R. Motor cortical plasticity in Parkinson's disease. Front Neurol. 2013;4:128.

74. Fremeau RT Jr, Troyer MD, Pahner I, Nygaard GO, Tran CH, Reimer RJ, et al. The expression of vesicular glutamate transporters defines two classes of excitatory synapse. Neuron. 2001;31(2):247-60.

75. Fujiyama F, Kuramoto E, Okamoto K, Hioki H, Furuta T, Zhou L, et al. Presynaptic localization of an AMPA-type glutamate receptor in corticostriatal and thalamostriatal axon terminals. Eur J Neurosci. 2004; 20(12):3322-30

76. Herzog E, Bellenchi GC, Gras C, Bernard V, Ravassard P, Bedet C, et al. The existence of a second vesicular glutamate transporter specifies subpopulations of glutamatergic neurons. J Neurosci. 2001;21(22):Rc181.

77. Varoqui $\mathrm{H}$, Schafer MK, Zhu H, Weihe E, Erickson JD. Identification of the differentiation-associated $\mathrm{Na}+/ \mathrm{PI}$ transporter as a novel vesicular glutamate transporter expressed in a distinct set of glutamatergic synapses. J Neurosci. 2002;22(1):142-55

78. Raju DV, Ahern TH, Shah DJ, Wright TM, Standaert DG, Hall RA, et al. Differential synaptic plasticity of the corticostriatal and thalamostriatal systems in an MPTP-treated monkey model of parkinsonism. Eur J Neurosci. 2008;27(7):1647-58.

79. Krebs CE, Karkheiran S, Powell JC, Cao M, Makarov V, Darvish H, et al. The Sac1 domain of SYNJ1 identified mutated in a family with early-onset progressive parkinsonism with generalized seizures. Hum Mutat. 2013;34(9): 1200-7.

80. Quadri M, Fang M, Picillo M, Olgiati S, Breedveld GJ, Graafland J, et al. Mutation in the SYNJ1 gene associated with autosomal recessive, earlyonset parkinsonism. Hum Mutat. 2013;34(9):1208-15.

81. Kirola L, Behari M, Shishir C, Thelma BK. Identification of a novel homozygous mutation Arg459Pro in SYNJ1 gene of an Indian family with autosomal recessive juvenile parkinsonism. Parkinsonism Relat Disord. 2016; 31:124-8.

82. Cao M, Wu Y, Ashrafi G, McCartney AJ, Wheeler H, Bushong EA, et al. Parkinson sac domain mutation in Synaptojanin 1 impairs Clathrin Uncoating at synapses and triggers dystrophic changes in dopaminergic axons. Neuron. 2017;93(4):882-96 e5.

83. Brunden KR, Lee VM, Smith AB 3rd, Trojanowski JQ, Ballatore C. Altered microtubule dynamics in neurodegenerative disease: therapeutic potential of microtubule-stabilizing drugs. Neurobiol Dis. 2017;105:328-35.

84. Sousa VL, Bellani S, Giannandrea M, Yousuf M, Valtorta F, Meldolesi J, et al. Alpha-synuclein and its A30P mutant affect actin cytoskeletal structure and dynamics. Mol Biol Cell. 2009;20(16):3725-39.

85. Koch JC, Bitow F, Haack J, d'Hedouville Z, Zhang JN, Tonges L, et al. AlphaSynuclein affects neurite morphology, autophagy, vesicle transport and axonal degeneration in CNS neurons. Cell Death Dis. 2015;6:e1811.

86. Lautenschlager J, Kaminski CF, Kaminski Schierle GS. Alpha-Synuclein regulator of exocytosis, endocytosis, or both? Trends Cell Biol. 2017;27(7): 468-79.

87. Takenouchi T, Hashimoto M, Hsu LJ, Mackowski B, Rockenstein E, Mallory M, et al. Reduced neuritic outgrowth and cell adhesion in neuronal cells transfected with human alpha-synuclein. Mol Cell Neurosci. 2001;17(1):141-50.

88. Del Tredici K, Braak H. Lewy pathology and neurodegeneration in premotor Parkinson's disease. Mov Disord. 2012;27(5):597-607.

89. Braak H, Del Tredici K. Neuropathological staging of brain pathology in sporadic Parkinson's disease: separating the wheat from the chaff. J Park Dis. 2017;7(s1):S71-85.

90. Braak H, Rub U, Gai WP, Del Tredici K. Idiopathic Parkinson's disease: possible routes by which vulnerable neuronal types may be subject to neuroinvasion by an unknown pathogen. J Neural Transm (Vienna). 2003; 110(5):517-36.

91. Foffani G, Obeso JA. A cortical pathogenic theory of Parkinson's disease. Neuron. 2018;99(6):1116-28.

\section{Publisher's Note}

Springer Nature remains neutral with regard to jurisdictional claims in published maps and institutional affiliations. 